\title{
Los concursos infraccionales en el Derecho administrativo sancionador chileno
}

\section{Chilean Punitive Administrative Law and Concurrent contraventions}

\section{Eduardo Cordero Quinzacara}

El trabajo analiza los problemas del concurso de infracciones administrativas en Chile, haciendo una relación con la doctrina y normas penales, las regulaciones sectoriales y los criterios que ha seguido la jurisprudencia. Se proponen las bases de un sistema aplicable a los concursos para atenuar la acumulación matemática, considerando las deficiencias regulatorias existentes.

Palabras clave: Infracciones administrativas, Sanciones administrativas, Concurso infraccional.
The paper analyzes the problems of concurrent contraventions in Chile. It makes a relation with the doctrine and penal norms, the sectorial regulations and the criteria of the jurisprudence. The bases of a system applicable to the competitions are proposed to attenuate the mathematical accumulation considering the existing regulatory deficiencies.

Keywords: Administrative contraventions, Administrative sanctions, Concurrent contraventions.

\section{Introducción}

La matriz de los principios y normas que debieran regir el Derecho administrativo sancionador ha dado lugar en Chile a una discusión que no reconoce siempre un punto de encuentro, ya que al separar radicalmen-

\footnotetext{
* Profesor Titular de Derecho Administrativo de la Facultad de Derecho de la Pontificia Universidad Católica de Valparaíso, Chile. Dirección postal: Pontificia Universidad Católica de Valparaíso, Facultad de Derecho, Avenida Brasil 2950, Valparaíso, Chile. Correo electrónico: eduardo.cordero@pucv.cl.

Este trabajo es parte de una investigación financiada por FONDECYT referida al proyecto "Criterios y estándares para el control de la potestad sancionadora de la Administración: análisis de los mecanismos de revisión judicial y administrativa" № 1201868; y del Proyecto DI Consolidado 37.0/2019, de la Vicerrectoría de Investigación y Estudios Avanzados de la Pontificia Universidad Católica de Valparaíso.
}

Artículo recibido el 27 de diciembre de 2019 y aceptado el 25 de mayo de 2020. 
te el mundo de lo "administrativo" de lo "penal", se produce una tensión que no otorga la seguridad necesaria en relación con los criterios que se deben aplicar y, por tanto, no existe una solución del todo satisfactoria. En efecto, el tratamiento y análisis del régimen de las infracciones administrativas ha estado dominado en nuestro país por un debate en relación con sus fundamentos, función y principios, que no está cerrado ${ }^{1}$, frente a una jurisprudencia que también ha dado cuenta de cambios de criterios al momento de resolver temas centrales, como es su relación con el Derecho penal y la aplicación de diversos principios que pretenden colmar los vacíos que existe en una fragmentada y diversa legislación especial ${ }^{2}$. Por eso no es de extrañar que exista una constante referencia desde el ámbito administrativo a los conceptos, técnicas, garantías y regulaciones propias del Derecho penal -ya sea para acercarse o marcar distancias-, y que ha servido como punto de referencia para construir -no sin tropiezos-, un sistema de sanciones que considere la particular posición y funciones que debe cumplir la Administración pública.

Ahora bien, todo este panorama produce una natural sensación de desasosiego y preocupación, al darnos cuenta que el "mundo de lo ilícito" está dominado principalmente por infracciones administrativas más que por los delitos, que en términos cuantitativos tienen una magnitud que es casi exponencial en relación con los ilícitos penales, recogidos en un puñado de leyes, partiendo por el Código penal. Y no puede ser de otra forma, pues existe la percepción de que los temas centrales de los ilícitos administrativos no están del todo resueltos -como ocurre con el concurso infraccional, y además existe una alta probabilidad de que podamos cometer una infracción administrativa antes que incurrir en algún tipo penal.

\footnotetext{
1 Si pudiéramos hacer una síntesis de la discusión, en una primera etapa se experimentó en nuestro país una suerte de "tolerancia o indiferencia constitucional" de las sanciones administrativas, no sin alguna crítica aislada (Hunneus 1891, vol. 3, pp. 230-231). Posteriormente, el tema fue abordado fundamentalmente por la doctrina penal, siguiendo los criterios y la discusión del Derecho comparado (Novoa 2005, pp. 36-40; CuRY 1979, pp. 86-94), teniendo presente lo dispuesto en el artículo 20 del Código Penal. Bajo la Constitución de 1980 el análisis fue mucho más agudo en orden a cuestionar su constitucionalidad (Sото KLOSS, 1979/1808, pp. 95-103; ARÓSTICA, 1987, pp. 71-81), hasta que comienza lentamente un proceso de racionalización de esta potestad (Rodríguez 1986, pp. 117-164; ArósticA, 1991, pp. 173-195; CuRY 2005, pp. 100114), que culmina con la sentencia Rol N²44/1996 del Tribunal Constitucional, reconociendo su legitimidad constitucional y la aplicación con matices de los principios constitucionales del orden penal, siguiendo la tendencia del Derecho español (VERGARA 2004, pp. 137-147). Luego de extenderse dicha posición en la jurisprudencia de Contraloría y la Corte Suprema (CORDERO 2013, pp. 79-103), comenzó lentamente un replanteamiento del tema sobre la base de la autonomía de las sanciones administrativas respecto de los principios y garantías del Derecho penal (Román 2008, pp. 107-136; Londoño 2014, pp. 147-167; VALLEJO y GUILOFF, 2013; VAN WeEZel 2017, pp. 9971043), que llegó a la jurisprudencia judicial y administrativa (vgr. casos de transmisibilidad de las multas, Corte Suprema Rol N 1079-2014, y los plazos de prescripción, Contraloría Dictamen $N^{\circ}$ 24.731, de 2019), con una versión más radical que difumina todo tipo de garantías (LETELIER 2017, pp. 622-689). Sin embargo, el Tribunal Constitucional volvió sobre los argumentos originales de la inconstitucionalidad de las potestades sancionadoras de la Administración, dejando abierto nuevamente el debate (Sentencias Roles Nos. 3.958-17 y 4.012-12).

2 Véase Fisco de Chile con Dörr Zegers (2014), considerando 9; Honorable Camara de Diputados (2017), considerandos $26^{\circ}$ y $27^{\circ}$ y Honorable CAMARA de Diputados (2018), considerandos $33^{\circ}$ a $39^{\circ}$.
} 
También existe la conciencia de que no estamos ante un fenómeno que sea pasajero, pues todo apunta a su consolidación, a partir de un dato que es bastante conocido: la existencia de una sociedad más compleja, debido a un desarrollo y crecimiento industrial, tecnológico y financiero cada vez más avanzado y sofisticado, que colocan necesariamente a la Administración en una función central dentro del Estado para poder asegurar que los valores y bienes constitucionales realmente se puedan cumplir, debiendo llevar adelante una tarea de conformación social cada vez más intensa, para lo cual el ordenamiento le entrega un amplio abanico de herramientas, una de las cuales es la potestad sancionadora.

De esta manera, cada nueva regulación que pretende disciplinar sectores relevantes en lo social y económico, nos deja una estela de tipos infraccionales que nos resulta imposible de conocer y que en muchas ocasiones la propia Administración no tiene los medios y recursos suficientes para aplicarla. Así, se recurre a fiscalizaciones selectivas o "matrices de riesgos" que sorprenden a los inadvertidos infractores que han tenido la mala fortuna de caer en la mira de los inspectores y que se convierten en la poca afortunada alerta que mantiene viva en la comunidad la finalidad disuasiva de la sanción. Como bien señala Alejandro Nieto "[...] no ya un ciudadano cualquiera, ni el jurista más estudioso ni el profesional más experimentado son capaces de conocer las infracciones que cada día pueden cometer [...] Nadie, por muy escrupuloso que sea puede alardear de no haber cometido alguna infracción administrativa. Nadie -cuando es detenido en la carretera por la policía de tráfico o visitado en su casa o empresa por los inspectores- pues estar seguro de salir ileso"3.

En este contexto, el ámbito de libertad de la cual gozan los ciudadanos se comienza a cerrar de forma abrupta. Y esto ocurre no por lo que constituía la principal amenaza para los revolucionarios liberales, como eran los tipos penales, sino por el exponencial desarrollo de los tipos infraccionales en el ámbito administrativo, frente a los delitos que constituyen verdaderas islas sujetas a una legalidad y taxatividad estricta. Una extendida, dispersa y creciente regulación de diversos sectores de la vida social, ha hecho difuminar esa idea de libertad que está en el sustrato del Derecho penal, cambiando hacia una sensación vital de encontrarnos en un estado infraccional permanente, haciendo de este sector un espacio propicio y más recurrente para la existencia de concursos infraccionales. De esta forma, existe una posibilidad cierta de incurrir en una pluralidad de hechos tipificados como infracción (concurso real infraccional) o que un hecho sea constitutivo de dos o más infracciones administrativas (concurso ideal infraccional).

Por tal razón el objetivo de este trabajo es determinar cómo tienen lugar las figuras concursales en el Derecho administrativo sancionador y cuáles son los criterios que se deberían tener presente para su resolución, para luego

\footnotetext{
${ }_{3}$ NIETO 2012, p. 27.
} 
determinar cómo han sido abordados por nuestra jurisprudencia y cuáles deberían ser las reglas o pautas de solución en nuestro Derecho positivo que, por lo demás, clama durante largo tiempo por una regulación básica sobre varios aspectos del régimen de este tipo de infracciones. Por ahora, las limitaciones de este estudio solo comprenden el problema en el ámbito de las infracciones administrativas, dejando para otra ocasión el análisis del concurso entre las infracciones administrativas y los delitos.

La hipótesis central de esta investigación postula que ante la inexistencia de una norma general en Chile que regule los concursos infraccionales, se pueden establecer criterios para atenuar la regla de la acumulación matemática de sanciones orientados a garantizar el principio de proporcionalidad que rigen en estas materias. Además, las deficiencias regulatorias no permiten ser superadas por la aplicación del principio non bis in ídem, que por su sentido y función no responde adecuadamente al problema de este tipo de concursos.

Para analizar este tema, será necesario examinar cómo se han desarrollado los conceptos y técnicas para analizar y dar solución al problema de las figuras concursales, particularmente en el Derecho penal (I); para luego comprender la forma en que se ha justificado la aplicación de estas categorías al ámbito del Derecho administrativo sancionador (II) y establecer cómo se producen estos concursos a partir de los conceptos de unidad y pluralidad de infracciones (III). Con estos elementos, nos detendremos en revisar la regulación en el Derecho comparado y nacional, para determinar sus principales vacíos y falencias (IV), para continuar con un análisis de la jurisprudencia relativa a las figuras concursales $(\mathrm{V})$, proponiendo, posteriormente, las bases para la construcción de un sistema de aplicación de dichas figuras al ámbito administrativo sancionador (VI), terminando con unas conclusiones.

\section{Las formas concursales: categorías y técnicas del Derecho penal}

La existencia de elementos comunes ente los delitos y las infracciones -al punto de sostenerse su identidad ontológica-, no significa necesariamente que deba aplicarse un mismo régimen jurídico, como bien lo ha sostenido la doctrina ${ }^{4}$ y la jurisprudencia nacional ${ }^{5}$. Sin embargo, los principios del orden penal han servido como herramienta para racionalizar el ejercicio de las potestades sancionadoras de la Administración, aunque fuese con "matices", considerando su particular naturaleza y función. Por lo demás, buena parte

\footnotetext{
${ }^{4}$ En este sentido, Alejandro Nieto sostendrá que "[...] decir que dos fenómenos son iguales en la realidad no significa que hayan de tener el mismo régimen jurídico; de la misma forma que el legislador puede dotar del mismo régimen jurídico a figuras que en el mundo real, sin duda alguna, ontológicamente diferentes". Así es "jurídicamente casi irrelevante, dado que la hipotética identidad ontológica metanormativa no garantiza una correlativa identidad de régimenes legales". NieTO 2005, p. 153 y 161.

5 Fisco de Chile con Dörr Zegers (2014), considerando $9^{\circ}$ y Dictamen No 24.731, de 2019, de Contraloría.
} 
de la batería de principios que comparte el Derecho penal y el Derecho administrativo sancionador provienen del Derecho público estatal y se pueden aplicar sin necesidad de recurrir a una categoría superior que los unifique, como ha sido la figura de la potestad punitiva única del Estado.

Por su parte, esta proximidad también responde al notable avance de la ciencia jurídico-penal en el análisis y comprensión de sus figuras centrales, como son el delito y la pena, a partir de técnicas, categorías y conceptos que se despliegan sobre la legislación positiva, incluso encontrando soluciones que superan su límite dogmático y la llevan a la teoría general del derecho. Por tal razón, no es de extrañar que muchas de estas herramientas también sean útiles para analizar y comprender las figuras de las infracciones y las sanciones administrativas ${ }^{6}$.

Ahora bien, estando muy trabada la relación entre derecho positivo y dogmática en el Derecho penal, es posible hacer la distinción entre uno y otro. De esa forma, si bien se puede discutir si corresponde aplicar los principios y normas del Derecho penal para resolver los problemas que plantean las infracciones administrativas, parece que la utilización de conceptos y categorías dogmáticas penales no presentan reparos tan serios o insuperables, en la medida que permiten resolver problemas similares en el ámbito administrativo. Por lo demás, muchos de estos principios están asociados en su implementación a determinadas técnicas o instrumentos que, dada sus características, no admiten una aplicación matizada, como sucede con el principio non bis in ídem, la prohibición de la retroactividad in pejus o, en el caso que nos interesa, con las figuras concursales ${ }^{7}$.

En esta línea, el Derecho penal ha consolidado históricamente sus principios a partir de un conjunto de normas que son depositarias de una larga tradición, que culmina con las revoluciones liberales. Y esto se aprecia claramente en el caso de las figuras concursales, que son objeto de preocupación y análisis desde la Baja Edad Media por parte de los juristas italianos a través

\footnotetext{
${ }^{6}$ En este sentido, Nieto sostiene que el Derecho Administrativo Sancionador no debe ser construido con los materiales y con las técnicas del Derecho penal, sino desde el propio Derecho administrativo, del que obviamente forma parte, y desde la matríz constitucional y del Derecho público estatal, pero a diferencia de lo que se podría pensar, afirma que "[...] en esta tarea la presencia del Derecho Penal es no ya solo útil sino imprescindible y ha de seguir operando, no obstante y en todo caso, como punto de referencia, como pauta técnica y, sobre todo, como cota de máxima de las garantías individuales que el Derecho Administrativo Sancionador debe tener siempre presentes" (NIETO 2005, p. 32). A su vez, destaca la prevalencia que tenido el Derecho penal sobre el Derecho administrativo sancionador por razones históricas, constitucionales y, particularmente, dogmáticas respecto de los principios que aporta al Derecho punitivo del Estado (NiETo 2005, p. 168).

7 La discusión matizada de los principios constitucionales del orden penal ha planteado una serie de dificultades en su aplicación al ámbito administrativo, especialmente en los principios de tipicidad, culpabilidad, proporcionalidad y del debido proceso administrativo. Sin embargo, en los casos citados, no es posible postular una aplicación matizada como sería, por ejemplo, respecto de la prohibición de doble valoración para unos casos y no para otros, lo mismo que en la aplicación de efectos desfavorables de forma retroactiva.
} 
del concursum delictorum, debido a la excesiva rigurosidad que planteaba la acumulación de penas en los casos de concurrencia de delitos. De esta forma, tienen lugar los primeros planteamientos para aplicar una sola pena, aunque aquella fuera más agravada ${ }^{8}$. Esta propuesta ejerció influencia en la Constitutio Criminalis Carolina de 1532, considerando como el primer y único Código Penal del Reich hasta 1870, y bajo cuya vigencia se desarrolla la teoría del concurso", que se consagra legislativamente en el Código penal bávaro de 1813 (parágrafos §107, §109 y §110), gracias al aporte de Paul Anselm von Feuerbach ${ }^{10}$, pasando posteriormente al Código Penal prusiano de 1851 y el Código Penal del Imperio Alemán de 1871.

Por su parte, las reglas para resolver el problema de los concursos delitos (acumulación material, absorción y exasperación) son recogidas en el Código Penal Español de $1822^{11}$, frente a los cuestionamientos del principio de que a cada delito le corresponda la aplicación de una pena (quot delicta tot poenae) $)^{12}$. Luego de varios proyectos, se aprueba el Código Penal de 1848 , en donde se formulan las bases de la regulación vigente respecto de la teoría de los concursos, haciéndose cargo del concurso ideal y medial de forma muy similar a los códigos posteriores ${ }^{13}$, incluyendo el actual Código Penal Español.

Es conocida la importancia de este cuerpo normativo en Chile, ya que constituye uno de los antecedentes directos del Código Penal de Chile de 1874. Por tal razón, no es de extrañar que reproduzca casi de forma literal las reglas sobre concurso material, ideal y medial en sus artículos 74 y 75. Así, siendo la regla general la acumulación material de penas, se considera una regla de absorción agravada para el concurso ideal y medial. En reformas

\footnotetext{
8 Se destacan en esta materia los aportes de Julius Clarus y, especialmente de Prosper Farinacius, quien era una juez que no se caracterizaba por ser benevolente. En todo caso, sus planteamientos reconocían como antecedente la línea iniciada por los postglosadores Bartolo de Sassoferrato y Baldo de Ubaldi. Véase GeERDS 1961, pp. 24-27; JeSCHECK y WeIGEND 1996, p. 708; CURY 2005, p. 654.

9 Se considera que Johannes Christoph Koch fue quien desarrolló por primera vez la teoría de concurso como actualmente se conoce, en sus Institutiones juris criminalis de 1758, distinguiendo entre concurso simultáneo (concurso ideal) frente al concurso sucesivo (concurso material). GeERDS 1961, pp. 41-42.

10 Son varios los aportes realizados por Feuerbach, al punto de ser reconocido como el fundador de la moderna ciencia de Derecho punitivo. Su planteamiento se puede ver en su obra Lehrbuch des gemeinen in Deutschland geltenden Peinlichen Rechts, cuya primera edición es de 1801.

11 Artículos 113 y 114.

12 SAnz 1986, p. 30.

13 Luego de establecer que "[...] al culpable de dos o más delitos o faltas, se impondrán todas las penas correspondientes a las diversas infracciones" (artículo 76), se dispone que dicha regla no es aplicable "en el caso de que un solo hecho constituya dos o más delitos, o cuando el uno de ellos sea medio necesario para cometer el otro" (artículo 77 inciso $1^{\circ}$ ). En este caso, el problema se resuelvo aplicando una absorción agravada: "se impondrá la pena correspondiente al delito mas grave, aplicándola en su grado máximo" (artículo 77 inciso 2%).
} 
posteriores se incorpora además una regla de exasperación para el concurso real, que complementa a las dos normas anteriores ${ }^{14}$.

En paralelo, se desarrolla desde mediados del siglo XIX la teoría del concurso aparente de leyes penales, que muchas veces se confunde con el concurso de delitos. Se atribuye a Merkel su conceptualización, aunque ya existían algunos estudios incipientes que abordaba el problema como una cuestión de determinación de la ley penal aplicable ${ }^{15}$. La construcción teórica la distingue del concurso real, donde hay una pluralidad de infracciones legales; y del concurso ideal, en que un mismo y único hecho solo agota su contenido penal bajo la subsunción en una pluralidad de leyes penales. En cambio, en el concurso (aparente) de leyes penales un hecho parece satisfacer las exigencias de dos o más tipos diversos, pero solo será regulado por uno de ellos a partir de determinados criterios o principios ${ }^{16}$ (especialidad, consunción, subsidiariedad y alternatividad) ${ }^{17}$. Se trataría de un problema de interpretación y que debe llevar a una solución única: la ley que resultaría aplicable a una determinada infracción y, por tanto, la pena correlativa. No nos corresponde ahora entrar en un análisis detenido de esta figura concursal, pero si debemos tenerla en consideración dentro del proceso lógico que exige la determinación de la sanción, que parte por establecer el hecho punible, la ley aplicable y, luego, los posibles concursos que se pueden presentar.

\section{La aplicación de las reglas de los concursos en el Derecho adminis- trativo sancionador}

Como se ha indicado, la opción metodológica de construir el Derecho administrativo sancionador a partir del Derecho público estatal no lo ha liberado necesariamente del recurso a las normas y técnicas del Derecho penal, aunque se ha tratado de restringir su alcance a supuestos excepcionales, como son: a) la analogía in melior, b) la declaración expresa de supletoriedad, y c) la remisión de la norma administrativa ${ }^{18}$.

Por su parte, se ha reconocido en los ordenamientos comparados la aplicación de las reglas de las figuras concursales del Derecho penal a las infracciones administrativas, considerando que esta disciplina dispone de una regulación más completa y consolidada, además de responder a principios

\footnotetext{
14 Esta regla fue incorporada por el artículo 537 Código de Procedimiento Penal de 1907: "En los casos de reiteración de simples delitos de una misma especie, se impondrá la pena correspondiente a las diversas infracciones, estimadas como un solo delito, aumentándola en uno, dos o tres grados". Posteriormente, fue complementada por la Ley $N^{\circ} 3.988$, de 1923, en los casos que resultaré más favorable la regla del artículo 74 del Código Penal, incorporando a las faltas (ahora artículo 509). Luego, la Ley $N^{\circ} 7.836$, de 1944, considerará también a los crímenes dentro de la regla de exasperación. Por último, el texto se mantuvo en el artículo 351 del actual Código Procesal Penal, comprendiendo también a las faltas (artículo 397). Véase Oliver 2013, pp. 169-170.

15 Con abundantes antecedentes y bibliografía, véase Matus 2000.

16 Cury 2005, p. 667.

17 Matus 2002, pp. 31-34.

18 Nieto 2011, p. 132.
} 
generales que forman parte del Derecho público del Estado, como sucede con la proporcionalidad en la reacción punitiva.

Sin embargo, la forma como opera esta recepción es diferente, dependiendo de cada ordenamiento:

a) En algunos países la solución se ha adoptado directamente por la legislación positiva, aplicando las reglas de absorción o exasperación, como sucede en el Derecho Alemán ${ }^{19}$, Italia ${ }^{20}$, España ${ }^{21}$ y en Latinoamérica con la legislación peruana22.

b) Como una regulación supletoria. Así, por ejemplo, el Tribunal Supremo Español ha sostenido en materia de concurso infraccional que "[...] en ausencia de norma específica en contra dentro del ordenamiento sancionador administrativo en la materia o del común administrativo, es adecuado a Derecho aplicar como norma subsidiaria de segundo grado los principios del derecho penal da la semejanza en materia regulada en él y el Administrativo sancionador" ${ }^{23}$. Por su parte, la doctrina tiende ir un poco más lejos, sosteniendo que la mayor parte de los principios y garantías que se predican del Derecho penal se deberían aplicar también, mutatis mutandi, a las infracciones y sanciones administrativas, en la medida en que los mismos sean compatibles con el cumplimiento de la función a la que estas últimas están destinadas ${ }^{24}$.

c) Por analogía in melior, como lo sostiene Alejandro Nieto dentro de las pautas generales para aplicar el Derecho penal ${ }^{25}$ y que, en esta materia, confirma Tomás Cano Campos al señalar que "[...] la aplicación de la teoría del concurso de infracciones parece clara en el Derecho administrativo sancionador, pues en favor de la misma no solo juega el ius puniendi único del Estado o la aplicación analógica del CP, sino la propia previsión de esta modalidad concursal en determinadas normas administrativas" 26 .

Sin embargo, todas estas posiciones descansan en una gran evidencia: la prevalencia dogmática que tiene el Derecho penal y que autorizan la utilización de sus conceptos y categorías. Pero, además, existe un elemento que es común, como es la aplicación del principio de proporcionalidad que debe guiar el ejercicio de los poderes punitivos ${ }^{27}$. Por tal razón, frente al problema

\footnotetext{
19 §19 y §20 de la Gesetz über Ordnungswidrigkeiten de 1987.

20 Artículo Octavo de la Ley $N^{\circ}$ 689, de 1981.

${ }^{21}$ Artículo 29.5 y 29.6 de la Ley 40/2015, de 1 de octubre, de Régimen Jurídico del Sector Público.

22 Artículo $230 \mathrm{~N}^{\circ} 6$ de la Ley N²7.444, del Procedimiento Administrativo General.

23 Sentencia del Tribunal Supremo de 9 de junio de 1999 (RJ 1999, 6394), F. 4º.

24 Gómez y SANZ 2017, p. 116.

25 NieTO 2011, p. 132.

26 Cano Campos 2001, p. 214.

27 En tal sentido, se ha señalado que: "En principio, el problema es idéntico al que se plantea en el Derecho Penal, por lo que ante la inexistencia de reglas generales en el Derecho Administrativo Sancionador, los criterios y soluciones que en aquel otro Derecho se han formado debieran
} 
de cómo enfrentar los concursos infraccionales, se nos señala con autoridad que en esta tarea "[...] contamos una vez más con la valiosa ayuda de los instrumentos técnicos del Derecho penal, que hay que utilizar sin reparos mientras el Derecho administrativo sancionador no esté en condiciones de crear sus propios remedios" 28 .

\section{Unidad y pluralidad de infracciones administrativas}

El análisis del concurso infraccional requiere determinar de forma previa en qué casos estamos frente a un hecho infraccional o frente a varios.

En una primera instancia la autoridad debe calificar jurídicamente determinados hechos que pueden ser constitutivos de infracción. Así, bien puede establecer que la conducta desplegada no se encuentra comprendida dentro del tipo infraccional, razón por la cual no procede aplicar sanción alguna (atipicidad de la conducta) ${ }^{29}$, o que estemos ante un hecho infraccional, caso en el cual se debe continuar con el procedimiento y determinar si procede aplicar la sanción. Luego, la regla general será que un hecho debiera dar lugar a una infracción; a su vez, varios hechos debieran dar lugar a varias infracciones (concurso real); pero también puede ocurrir que un hecho constituya dos o más infracciones (concurso ideal). En los dos últimos casos, estaremos ante una pluralidad de infracciones.

En todo caso, el concepto de hecho no se toma en sentido naturalista, como la acción natural desplegada por un ser humano, sino que se debe hacer en sentido jurídico o valorativo ${ }^{30}$, es decir, como la ley configura el tipo infraccional, ya que el hecho puede comprender una sola acción u omisión (unidad natural de acción) o varias acciones y/o omisiones (unidad jurídica o normativa de acción) ${ }^{31}$, como sucede con varios tipos de infracciones, como son las infracciones complejas, permanentes, con pluralidad de acciones, con tipicidad reforzada y las infracciones continuadas, las cuales analizaremos más adelante ${ }^{32}$.

Por lo tanto, un hecho infraccional puede comprender una pluralidad de acciones, ya sea en sentido natural o que sean unificadas jurídicamen-

\footnotetext{
servir como referentes, a salvo de las soluciones específicas establecidas por alguna legislación sectorial", en IzQuierdo 2001, 232.

28 Nieto 2011, p. 480. Posteriormente, agrega: "Y no es poca la fortuna de contar con la teoría penal, dado que, de no ser por ella, habrían los administrativistias de explorar a ciegas estos nuevos caminos sin otro guía que el cuestionable voluntarismo de la casuística jurisprudencial ni otra luz que sus intuiciones personales".

29 Véase Sociedad Almondale Valle SpA con Superintendencia de Educación (2018).

30 MIR 2010, pp. 638-639.

31 Roxin 2014, pp. 943-962; CuRy 205, pp. 650-653.

32 En esta distinción se sigue de cerca la doctrina penal, por todos Roxin 2014, pp. 328-341, MIR 2010, pp. 223-231 y CURY 205, pp. 651-653; y que ha sido tomada por los administrativistas, con las debidas adecuaciones. Véase De Palma del Teso 2001, 556-557 y BACA 2011, pp. 268-270, especialmente para efectos del computo del plazo de la prescripción.
} 
te. A su vez, existirá pluralidad de infracciones cuando un hecho pueda ser encuadrado en más de un tipo infraccional o que se realicen varios hechos, todos las cuales encuadren en diversos tipos infraccionales, no habiendo sido sancionado ninguno de ellos previamente. Así, podemos definir el concurso infraccional como aquellos casos en que un hecho constituye dos o más infracciones administrativas o cuando dos o más hechos realizados por un mismo sujeto constituyen dos o más infracciones, sin que ninguno de ellos se hubiese cometido después de haber sido sancionado por alguno de ellos. En el primer caso, estamos frente a un concurso ideal de infracciones, mientras que en el segundo nos encontramos ante un concurso real.

\section{La regulación de los concursos infraccionales}

Como hemos señalado, las problemáticas a que dan origen a las figuras concursales en el orden penal también se presentan en el ámbito administrativo sancionador de forma bastante similar, por lo que la doctrina y algunos ordenamientos se han hecho cargo de forma expresa del tema.

\section{El concurso infraccional en el Derecho comparado}

El Derecho comparado se considera que el concurso de infracciones es una construcción jurídica que tiene una finalidad similar al orden penal: evitar un castigo desproporcionado ante uno o más ilícitos ${ }^{33}$. Es por tal razón, se han aplicado las categorías del Derecho penal para resolver estos casos, procurando atenuar la mera suma aritmética de sanciones. Así, para la doctrina española existe un concurso de infracciones cuando un sujeto ha cometido una pluralidad de infracciones por las que no ha sido sancionado previamente ${ }^{34}$. Por lo tanto, para agotar el injusto del o los hechos es preciso aplicar todas las consecuencias jurídicas previstas en la ley, puesto que de esta manera se dará protección a los bienes jurídicos afectados. Por consiguiente, existirá concurso real de infracciones cuando se realicen dos o más acciones que constituyan dos o más infracciones distintas, aunque presenten alguna conexión material ${ }^{35}$, así, una pluralidad de hechos supone una pluralidad de infracciones $^{36}$. De esta forma, se aplicarán las sanciones previstas para cada una de las distintas infracciones cometidas ${ }^{37}$. Por tal razón, la jurisprudencia ${ }^{38}$ y la doctrina ${ }^{39}$ sostienen que en el caso del concurso real de infracciones

\footnotetext{
33 AlarCón 2010, 769.

34 Gómez y Sanz 2017, 596.

35 Rebollo et al. 2010, 375.

36 CANO 2001, 244.

37 CANO 2010, 567.

38 Sentencia del Tribunal Superior de Justicia de Castilla y León, Burgos, de 20 de mayo de 2005 (Ar. 798 de 2006), en este caso se habían impuesto dos multas: una por arrancar de un monte ciertas especies arbóreas y la otra por su posterior rotulación sin autorización administrativa. Otras sentencias al respecto se pueden revisar en ReBollo et al. 2010, 374 y ss.

39 Alarcón 2010, 768.
} 
la regla general es la acumulación o suma de los castigos previstos para cada infracción.

Por su parte, el concurso ideal de infracciones se configura cuando se realiza un solo hecho que implica la comisión de dos o más infracciones, es decir, lesionando dos o más bienes jurídicos diferentes o el mismo bien jurídico dos veces ${ }^{40}$. Ahora bien, normalmente estos supuestos encuentran una solución legal, pero en caso contrario se tiende a aplicar la suma de castigos de forma matemática ${ }^{41}$, sobre la base de que no se aplicaría el principio non bis in ídem.

En el caso del concurso medial de infracciones nos encontramos frente a un concurso real -dos hechos y dos infracciones- que tienen lugar cuando una se comete como medio o instrumento necesario para realizar otra distin$\mathrm{ta}^{42}$. En este caso, el primer ilícito tiene como objeto o es un elemento necesario para la ocurrencia del segundo, de tal manera de que sin él, el segundo no hubiese acontecido ${ }^{43}$. Por tal razón, se castigan las infracciones con la sanción asignada a la infracción más grave ${ }^{44}$.

Desde el punto de vista del Derecho positivo, en el Derecho alemán la Ley de Infracciones Administrativas de 1987 (Gesetz über Ordnungswidrigkeiten) establece como regla general la acumulación material ${ }^{45}$, salvo en los casos de concurso ideal, en el cual se reconoce la absorción, es decir, se aplica la multa más alta ${ }^{46}$.

En el caso de Italia la Ley $N^{\circ}$ 689, de 1981, nada se dice respecto del concurso real, mientras que para el concurso ideal se aplica la técnica de la exasperación: la sanción prevista para la infracción más grave, aumentada al triple ${ }^{47}$.

\footnotetext{
40 Rebollo et al. 2010, p. 388

41 Sentencia del Tribunal Superior de Justicia de Asturias, de 20 de enero de 1998 (Ar. 53), en la cual se aplica la regla general de la suma de castigos por verter aguas residuales sin autorización. En este caso la empresa fue sancionada por la autoridad hídrica (afectación del dominio público hidráulico) y por la de pesca (por afectar la pesca fluvial).

42 Rebollo et al. 2010, 390. También en Cano 2010, 567.

43 Nieto trata el concurso medial en el capítulo que analiza la "prohibición de bis in ídem", explica que en este caso la comisión de un delito no supone un fin por sí mismo, sino que se trata simplemente de un medio para realizar otro, en NIETO 2012, 486. Véase Sentencia del Tribunal Superior de Justicia de Madrid, de 13 de mayo de 2004 (Ar. 992 de 2005). En este caso se había sancionado a una empresa con dos multas, una por verter hidrocarburos en las aguas de un puerto y la otra por incumplir el plan de emergencias a bordo en caso de contaminación por hidrocarburos. Según el Tribunal había una relación medial entre las conductas, esto es, un grado de relación y de conexión entre las mismas que ameritaba que la Administración solo sancionara por la infracción más grave (vertido) y no imponer sanción por la más leve.

${ }^{44}$ En este caso hay norma legal expresa en el artículo 29.5 de la Ley 40/2015, de 1 de octubre, de Régimen Jurídico del Sector Público.

$45 \S 20$.

$46 \S 19$ (2). Véase Mitsch 1995, pp. 139-147.

47 Artículo Octavo. Véase Nieto 2012, p. 483.
} 
En España la Ley 40/2015, de 1 de octubre, de Régimen Jurídico del Sector Público, se ocupa solo del concurso medial, imponiendo la sanción correspondiente a la infracción más grave (absorción) ${ }^{48}$, aunque también se discute si la misma regla se aplica al concurso ideal ${ }^{49}$. Además, también se hace cargo de establecer los criterios para determinar si la infracción puede ser considerada como continuada ${ }^{50}$. En todo caso, esto no impide que en leyes especiales se establezca una regulación particular al respecto ${ }^{51}$.

Por último, en Latinoamérica destaca la legislación peruana, que el caso del concurso ideal aplica una regla de absorción en relación con la infracción de mayor gravedad ${ }^{52}$.

\section{El concurso infraccional en el Derecho chileno}

Chile no cuenta con una ley general sobre infracciones y sanciones administrativas que se haga cargo -entre otros temas- de los problemas que plantea el concurso infraccional. Tampoco la legislación sectorial se hace cargo del tema, a diferencia de lo que sucede en los ordenamientos comparados.

La única disposición que trataría en parte el problema sería el inciso $1^{\circ}$ artículo 60 de la Ley $\mathrm{N}^{\circ}$ 20.417, sobre nueva Institucionalidad Ambiental, el cual dispone que: "Cuando por unos mismos hechos y fundamentos jurídicos, el infractor pudiese ser sancionado con arreglo a esta ley y a otra u otras leyes, de las sanciones posibles, se le impondrá la de mayor gravedad". Sin embargo, esta norma regula un problema de concurso aparente de leyes o de concurrencia normativa, es decir, cuando dos o más leyes sancionan un mismo hecho como infracción administrativa y sobre la base del mismo fundamento o, dicho en otros términos, el hecho parece satisfacer las existencias de dos o más tipos infraccionales diversos, pero solo será regulado por uno de ellos, desplazando a los demás. En este caso, el legislador opta por el principio de consunción: la infracción más grave consume o absorbe a la menos graves, frente a otros principios que ha desarrollado la doctrina ${ }^{53}$.

El concurso aparente de leyes se distingue de las formas concursales, ya que estamos ante un solo hecho infraccional y no ante una pluralidad de hechos que dan lugar a pluralidad de sanciones, como sucede en los casos de concurso real. A su vez, nos encontramos ante una sola infracción y no ante dos o más infracciones, como sucede en el concurso ideal.

\footnotetext{
48 Artículo 29.5.

49 Gómez y SANZ 2017, p. 598.

50 El artículo 29.6. dispone que "será sancionable, como infracción continuada, la realización de una pluralidad de acciones u omisiones que infrinjan el mismo o semejantes preceptos administrativos, en ejecución de un plan preconcebido o aprovechando idéntica ocasión".

51 Así, la Ley General Tributaria establece para el concurso real la acumulación material de sanciones (artículo 180.3); la Ley de Costas aplica para el concurso ideal la regla de la absorción (articulo 94.2), lo mismo que la Ley de Puertos del Estado (artículo 119.2).

52 Artículo $230 \mathrm{~N}^{\circ} 6$ de la Ley N²7.444, del Procedimiento Administrativo General.

53 Sobre la materia, véase MATUs 2000, p. 295 y CURY 2005, pp.667-671, con abundante referencia bibliográfica. Desde la perspectiva administrativa, CANO 2010, p. 566.
} 
En materia educacional, la Ley $N^{\circ} 20.529$, sobre sistema nacional de aseguramiento de la calidad de la educación parvularia, básica y media y su fiscalización, establece en su artículo 72 inciso $3^{\circ}$ que: "Si correspondiere sancionar un hecho que constituya una infracción a más de alguna ley de la normativa educacional, el Director Regional aplicará la sanción que corresponda como si se tratara de una sola infracción". En este caso se pueden comprender los supuestos de concurso aparente de leyes infraccionales y de concurso ideal. Sin embargo, no se entrega un criterio de solución, pudiendo ser en el primer caso la regla consunción, mientras que en el segundo se debiera aplicar la regla de la absorción, es decir, se debe optar por la sanción más grave, entendiendo que la voluntad de legislador no solo se expresa en castigar una determinada conducta, sino que también hacerlo de la forma más estricta, particularmente si estamos ante figuras concursales.

Por otra parte, a pesar de la ausencia de regulación legal, algunos órganos administrativos han hecho aplicación de las reglas de los concursos, como sucede con la Dirección del Trabajo que mediante una norma interna ha regulado un supuesto de concurso real de infracciones administrativas laborales de la misma especie, esto es, que afecten un mismo bien jurídico, disponiendo la acumulación jurídica de las diversas sanciones de multa ${ }^{54}$. A pesar de la dudosa legalidad y los efectos vinculantes de este tipo de regulación, los tribunales han considerado su aplicación en algunos de sus pronunciamientos ${ }^{55}$.

\section{Análisis de la jurisprudencia}

Nuestra jurisprudencia no tiene un criterio uniforme para resolver los problemas que plantea el concurso infraccional, teniendo como elementos de referencia el principio de legalidad, el principio de prohibición de doble valoración o non bis in ídem y el principio de proporcionalidad, como veremos a continuación.

\section{Concurso real o material de infracciones}

El principio de legalidad aparece con relación al concurso real o material de infracciones, es decir, frente a cada hecho infraccional se debe aplicar una

\footnotetext{
54 Apartado 8.5 de la Circular $N^{\circ}$ 46, de 2 de mayo del 2012, que determina el texto del "Anexo 10: Normas y criterios para resolver solicitudes de reconsideración de multas administrativas". En este caso se dispone lo siguiente: "Criterio para apreciar la rebaja en los casos de concursos de multas por infracciones de la misma especie. En aquellos casos de resoluciones de multas aplicadas por infracciones a una materia específica, se deberán subsumir o agrupar todas las multas como una sola infracción. Cuando estas multas sean de montos variables, se deberá mantener solo aquella de mayor valor, para proceder aplicar sobre ésta la pauta general de rebaja y los criterios específicos de reconsideración, dejándose sin efecto el resto".

Documento disponible en: http://www.dt.gob.cl/legislacion/1611/articles-101098_recurso_2.pdf

55 Véase Esteban Guic y Compañía Ltda. con Inspección Provincial del Trabajo Coyhaique (2016), del Juzgado de Letras del Trabajo de Coyhaique (considerando $7^{\circ}$ ), el cual fue confirmado por la Corte de Apelaciones de Coyhaique, en la causa Esteban Guic y Compañía Ltda. con Inspección Provincial del Trabajo Coyhaique (2017) (considerando $8^{\circ}$ ).
} 
sanción, por tanto, ante una pluralidad de hechos se debe aplicar la misma cantidad de sanciones, dando lugar a una acumulación aritmética. Para tal efecto, es importante determinar si las conductas que se persiguen constituyen o no un hecho infraccional, considerando que puede existir una pluralidad de acciones $u$ omisiones comprendidas dentro de un hecho punible $y$, además, por los problemas que se presentan en aquellos supuestos en que se aplica a un mismo infractor dos o más sanciones por hechos similares. Así las cosas, la jurisprudencia ha tenido en consideración diversos factores para poder identificar el hecho infraccional, como es el momento o en el lugar en que se produce la acción, así como el sujeto pasivo sobre el cual recae ${ }^{56}$. Por tal razón, se ha señalado que cuando la norma habla de "infracciones" o se basa en su existencia para imponer sanciones, se refiere, naturalmente, a

\footnotetext{
56 Así se ha señalado que "[...] si bien la infracción es la misma [...] no es menos cierto que los hechos se vinculan a trabajadores diferentes y se corresponden a unidades productivas diferentes aun cuando se corresponda con mismo giro y pertenezcan a una misma empresa o grupo empresarial, sin que la proximidad física de una y otra sea de mérito suficiente para eximirlo de responsabilidad respecto de las infracciones posteriores a la que primeramente se hubiere cometido, dado que cada una de ella tiene su propia unidad, sin que las previas, purguen las subsiguientes", Rendic Hermanos S.A. con Dirección del Trabajo (2020); "[...] solo cabe consignar que la Superintendencia de Educación ha exigido la acreditación de saldos por diferentes subvenciones y por períodos diferentes, por lo cual en ningún caso se le está sancionando por el mismo hecho", Corporación Municipal de Educación Salud Cultura y Atención al menor de Quilpué con Superintendencia de Educación (2019); “[...] no es posible aceptar que exista una identidad de hechos y de fundamentos en la imposición de las multas y como consecuencia de ello, no puede considerarse vulnerado el principio de non bis in ídem. Es más, las conductas infraccionadas ni siquiera pueden considerarse normativamente como una sola como alega el recurrente, toda vez que incluso se encuentran sancionadas en disposiciones legales diferentes", Administradora de Naves Humboldt Limitada con Inspección Provincial del Trabajo de Valparaíso (2018); "[...] ambas sanciones responden a circunstancias fácticas diversas, esto es, en un caso se castiga a la empresa como consecuencia de la falta de señalética que represente los riesgos de manipulación de la máquina así como por la ausencia de un procedimiento escrito que especifique la tarea de ajuste y/o calibración de la máquina raspadora de tripas, mientras que la autoridad encargada de la fiscalización de la normativa laboral reprocha al empleador no registrar la asistencia del profesional a cargo de la prevención de los riesgos así como por no suprimir los factores de peligro en los lugares de trabajo al no ser evaluado el riesgo de atrapamiento en la calibración de la máquina raspadora de tripas", Procesadora Insuban Limitada con Secretaría Regional Ministerial de Salud de la Región Metropolitana (2017); "[...] no nos encontramos frente a un mismo hecho, puesto que en definitiva se trata de infracciones cometidas a distintos dependientes, en unidades de trabajo o sucursales igualmente diferentes", Farmacias Cruz Verde S.A. con Inspección Comunal del Trabajo de Viña del Mar (2016); "[...] si la sanción motivo de la multa es constatada en un lugar, y la misma infracción es recurrente en otro local de la cadena, en este caso de Farmacias, es perfectamente lógico que la multa pueda ser replicada", Farmacias Cruz Verde S.A. con Inspección Provincial del Trabajo (2015); "[...] la infracción de no llevar el control de asistencia correctamente se produce, en los hechos, de manera distinta y afecta a trabajadores distintos, de obras distintas, ubicadas en zonas geográficas o emplazamientos distintos, y que cumplen funciones diversas.", Concremag S.A. con Inspección Provincial del Trabajo de Magallanes (2015); "[...] cada multa aplicada, dice relación no solo con farmacias diversas, sino también con trabajadores diversos", FASA Chile S.A. con Inspección Provincial del Trabajo (2015); "[...] cada una de ellas importan la infracción de una norma en particular, y en aquellos casos en que se invoca una misma norma aplicable, aparece que la fiscalización corresponde a hechos distintos, en términos que fueron fiscalizados buses diferentes, de recorridos diferenciados y conducidos por trabajadores distintos." Empresa de Transportes Rurales Ltda con Inspección del Trabajo de Antofagasta (2016).
} 
hechos; y esos hechos deben ser, para poder separarse en infracciones diversas, independientes unos de otros de modo que en el caso concreto pueda concebirse la producción de uno, sin los otros ${ }^{57}$. Así, se puede estar ante infracciones similares, respecto de las que resultan aplicables las mismas normas, pero respecto de hechos que son diversos, pudiendo afirmarse -como ha dicho una sentencia- que estamos en presencia de un concurso real de infracciones administrativas ${ }^{58}$.

Ahora bien, el problema es determinar si la acumulación matemática se puede atenuar recurriendo a la regla de exasperación prevista en la legislación procesal penal ${ }^{59}$. En este caso, en el caso Pascual Lama ${ }^{60}$, el Segundo Tribunal Ambiental negó dicha posibilidad, por falta de norma legal que lo regulara ${ }^{61}$. Sin embargo, en materia laboral los tribunales no han planteado

57 Sociedad Patricio Otero y Compañía Limitada con Inspección Comunal del Trabajo de Viña del Mar (2016).

58 Empresa de Transportes Rurales Ltda con Inspección del Trabajo de Antofagasta (2016), considerando $6^{\circ}$.

59 Artículos 351 y 397 del Código Procesal Penal.

60 Rubén Cruz Pérez y otros en contra de la Superintendencia del Medio Ambiente (2013). Dicha sentencia declaró que la Superintendencia del Medio Ambiente (SMA) incurrió en un vicio de ilegalidad al sancionar los incumplimientos a la Resolución de Calificación Ambiental (RCA) como una sola infracción y considerar los demás eventos como agravantes. Por tal razón, se anuló la resolución sancionatoria y se ordenó que se dictara una nueva, debidamente fundamentada, debiendo esa entidad sancionar cada uno de los incumplimientos en forma independiente.

Los argumentos expuestos por el Tribunal pueden resumirse en los siguientes puntos: i. La regla general en el sistema sancionatorio es que cada infracción sea sancionada independientemente, salvo norma expresa en contrario (c. 62); ii. En la ley orgánica de la SMA no hay ninguna norma que establezca explícitamente la existencia de un concurso de infracciones, de manera que la aplicación supletoria de las reglas legales sobre concurso de delitos contenidas en el Código Penal, como son los artículos 75 y 451, u otras reglas concursales como la contenida en el artículo 351 del Código Procesal Penal, requieren necesariamente de una norma expresa de remisión por parte de la ley (c. 46); iii. Tampoco procede reconocer la existencia del "concurso infraccional imperfecto", figura que carece de una norma que expresamente la institucionalice y que no fue indicada en la resolución que se recurre, sino que fue incorporada posteriormente como un alegato de defensa de la SMA ante el Tribunal (c. 47 y ss.), y iv. El Tribunal descarta que se trate de un caso de "infracción continuada", toda vez que aun cuando no se encuentra regulada expresamente y en el caso que su aplicación fuera posible en virtud del principio de proporcionalidad, no reúne los requisitos que tanto la doctrina como la jurisprudencia han elaborado para su símil penal, el delito continuado (c. 52 y ss.). El mismo criterio se aplicó en el caso Sociedad Eléctrica Santiago S.A contra Superintendencia del Medio Ambiente (2014), considerandos $42^{\circ}$ y $43^{\circ}$. Cabe señalar que la Corte Suprema no se pronunció al respecto en ambos casos.

${ }^{61}$ En un sentido similar, la Corte Suprema ha señalado que "[...] las infracciones imputadas a la reclamante corresponden a vulneraciones distintas e independientes entre sí, pues responden a hechos diferentes y se encuentran vinculadas a deberes diversos, aunque contemplados en una misma Resolución de Calificación Ambiental, acto resolutorio y complejo a cuyo respecto concurren "tantas voluntades como pronunciamientos sectoriales se vinculen a la resolución final", de lo que se sigue que tales infracciones requieren la imposición de sanciones diferentes, como acertadamente decidió la autoridad ambiental, pues se trata de reprimir hechos distintos e independientes entre sí". Sociedad Marítima y Comercial Somarco Limitada con Comisión Regional del Medio Ambiente de Arica y Parinacota (2018), considerando $14^{\circ}$. 
reparos a este respecto frente al criterio de acumulación jurídica seguido por la Dirección del Trabajo, como ya lo hemos visto ${ }^{62}$.

\section{Concurso aparente de leyes}

Una vez determinado el hecho infraccional, puede resultar que aquel sea subsumible en dos o más leyes sancionadoras, es decir, que nos encontremos ante un concurso aparente de leyes. Así, se dirá que en el concurso aparente convergen para solucionar el problema un conjunto de normas, si bien una sola de ellas, que desplaza a las demás, es suficiente para agotar el desvalor de la conducta ${ }^{63}$. La situación es distinta a lo que sucede en el concurso real de infracciones, ya que en este caso estamos frente a un solo hecho infraccional, pero ante una pluralidad de leyes sancionadoras. A su vez, se diferencia del concurso ideal de infracciones, porque frente a un hecho que produce una pluralidad de infracciones, en este caso estamos frente a un hecho infraccional y a una sanción prevista en una ley que desplaza a las demás. Por tal razón, uno de los fundamentos del concurso aparente es el principio non bis in ídem, como lo ha reconocido nuestra jurisprudencia en el ámbito de los servicios públicos sanitarios ${ }^{64}$ y eléctricos ${ }^{65}$, en donde un tipo infraccional es desplazado por otro tipo infraccional similar pero más agravado. Por tal razón, se sostiene que "[...] la notoria existencia de normas sancionadoras superpuestas no conculcan ese principio [...] ya que su cumplimiento corresponde no al que elabora y aprueba la norma, sino al que la aplica en aquellos supuestos en que un mismo acto o hecho puede estar tipificado y sancionado en más de un precepto punitivo"66, considerando dicho principio como

62 Esteban Guic y Compañía Ltda. con Inspección Provincial del Trabajo Coyhaique (2016), del Juzgado de Letras del Trabajo de Coyhaique (considerando $7^{\circ}$ ), el cual fue confirmado por la Corte de Apelaciones de Coyhaique, en la causa Esteban Guic y Compañía Ltda. con Inspección Provincial del Trabajo Coyhaique (2017) (considerando $8^{\circ}$ ).

63 Empresa de Transportes Rurales Ltda con Inspección del Trabajo de Antofagasta (2016): Corte de Apelaciones de Antofagasta, 18 de noviembre de 2016. Rol No 172-2016, considerando $6^{\circ}$.

${ }^{64}$ En este caso la discusión se planteaba respecto de las infracciones previstas en las letras a) y b), inciso primero, del artículo $11^{\circ}$ de la Ley $N^{\circ} 18.902$, que crea la Superintendencias de Servicios Sanitarios. La Corte Suprema sostuvo que "[...] la letra b), en esencia, constituye el mismo ilícito infraccional, pero agravado, toda vez que, como sucede en el caso concreto, la deficiencia en la calidad, continuidad u obligatoriedad del servicio de recolección de aguas servidas puso en peligro o afectó gravemente la salud de la población" (Aguas Antofagasta S.A. con Superintendencia de Servicios Sanitarios (2017), considerando $9^{\circ}$ ). En todo caso, erróneamente se califica este caso como un concurso ideal, señalando que: "[...] en la especie, se produce un concurso ideal de infracciones, en el que la infracción más grave absorbe o subsume a la de menor entidad, cuestión que, además, de la aplicación del principio non bis in ídem tiene su origen en el respeto del principio de proporcionalidad, que irradia todo el ámbito del Derecho Público sancionador" (considerando $7^{\circ}$ de la sentencia de reemplazo).

65 GasAtacama Chile S.A. con Superintendencia de Electricidad y Combustibles (2020), considerando $15^{\circ}$. Así, se ha señalado que "[...] no resulta posible asimilar el concepto "información errónea", que emplea la autoridad al sancionar a la actora, a la expresión "información falseada", que se lee en el $N^{\circ} 2$ del artículo 15 transcrito previamente, de lo que se sigue que la infracción imputada a GasAtacama no puede ser calificada de gravísima".

66 Inspección Comunal del Trabajo con Faenadora San Vicente Ltda. (2009): Corte Suprema, 24 de marzo de 2009. Rol No 196-09, citando a Rebollo Puig 1989. En el mismo sentido Sociedad de 
"[...] un criterio de interpretación o solución al constante conflicto entre la idea de la seguridad jurídica y la búsqueda de la justicia material"b7.

\section{Concurso ideal de infracciones}

El concurso ideal de infracciones ha sido tratado por la jurisprudencia a partir de las alegaciones formuladas sobre la base del principio non bis in ídem. En efecto, luego de analizar si concurren los supuestos para su aplicación, esto es, la triple identidad de sujeto, de hecho y fundamento, en varios casos se ha descartado este último en razón de que las infracciones protegerían bienes jurídicos diversos ${ }^{68}$. Esto trae como consecuencia que nos encontremos ante un hecho que da lugar a una pluralidad de infracciones, es decir, a un concurso ideal infraccional. Dada la situación, nuevamente el problema es determinar los criterios se deben seguir para determinar la sanción aplicable. Lo que resulta llamativo es que la jurisprudencia en estos casos se inclina también por la acumulación aritmética de sanciones. Así se dirá "[...] un mismo hecho no puede ser sancionado mediante la aplicación de dos normas que configuran más de una infracción, si éstas tienen un mismo fundamento. A contrario sensu, si los hechos o el fundamento son diferentes, no solo no hay impedimento para aplicar las dos sanciones, sino que necesariamente ellas deben ser aplicadas"69. Esto se ha presentado especialmente respecto de las sanciones que aplican las Secretarias Regionales Ministeriales de Salud y la Inspección del Trabajo70; las Secretarias Regionales Ministeriales de Salud

Tercerización de Servicios Provider Latin American Limitada con Inspección Comunal del Trabajo de Santiago Norte de Chacabuco (2009): Corte de Apelaciones de Santiago, 18 de mayo de 2016. Rol N430-2016.

67 Ídem, citando a DE LEÓN 1998.

68 Así se ha señalado que "[...] el principio non bis in ídem no prohíbe que una persona pueda ser castigada doblemente por unos mismos hechos si la imposición de una y otra sanción, responden a distinto fundamento y en el presente caso los dos hechos son distintos y a la vez tienen distinto fundamento", Instituto Alemán de Puerto Montt con Inspección del Trabajo de Puerto Montt (2016).

69 Empresa Nacional de Electricidad S.A. c. Superintendencia del Medio Ambiente (2015). En el mismo sentido, se dirá: "Esta prohibición de la acumulación de calificaciones jurídicas sancionadoras, discurre sobre la base que sobre el mismo sustrato valorativo y respecto de un mismo hecho, sea sancionado doblemente; esto es, prohibición de doble sanción desde una misma perspectiva valorativa por los mismos hechos cuando concurra, además, identidad de sujeto y de fundamento, lo que en la especie no ocurre, pues como se ha señalado, los procedimientos en que se hace consistir la doble sanción, descansan en sustratos fácticos diversos, acaecidos en distintos lapsos de tiempo, por lo que no se aprecia en el caso sub lite la vulneración alguna del señalado principio". VTR Wireless S.A. con Ministro de Transportes y Telecomunicaciones (2014).

70 En tal sentido, la Corte Suprema ha señalado que: "[...] como se desprende de la sola lectura de las disposiciones que rigen su actuar, ambas autoridades proceden en resguardo y defensa de intereses y bienes jurídicos diversos. En un caso se trata de velar por la aplicación de las medidas necesarias para proteger eficazmente la vida y salud de los trabajadores, mientras que en el segundo la actuación de la autoridad obedece a un deber impuesto al Servicio Nacional de Salud en orden a velar porque se eliminen o controlen todos los factores, elementos o agentes del medio ambiente que afecten la salud, la seguridad y el bienestar de los habitantes de la $\mathrm{Na-}$ ción en general, incluyendo entre los diversos sitios por cuyas condiciones de saneamiento y seguridad deberá preocuparse, además de ciudades, balnearios, campos y territorios mineros, los 
y la Superintendencia de Servicios Sanitarios ${ }^{71}$, y la Superintendencia de Educación con la Inspección del Trabajo ${ }^{72}$ respecto de un mismo hecho infraccional. Sin embargo, hay casos en los que se ha aplicado la regla de absorción

lugares de trabajo. [...] Que, en consecuencia, resulta evidente que ambas autoridades han intervenido en el caso en examen en ejercicio de sus atribuciones propias y en defensa de distintos bienes jurídicos, lo que permite descartar de plano la concurrencia en la especie de una infracción al invocado principio non bis in ídem" Verdenova S.A. con Secretaría Regional Ministerial de Salud de la Región Metropolitana (2016), considerandos $8^{\circ}$ y $9^{\circ}$ ). En el mismo sentido, Procesadora Insuban Limitada con Secretaría Regional Ministerial de Salud de la Región Metropolitana (2017), considerando 8; Constructora Nueva Tarapacá S.A. con Secretaría Regional Ministerial de Salud de la Región Metropolitana (2018), considerando $2^{\circ}$.

71 Aguas Araucanía S.A. con Secretaría Regional Ministerial de Salud de la Región de la Araucanía (2018). En este caso se planteó un problema de competencias y de vigencias de las normas del Código Sanitario en relación con las empresas sanitarias, sometidas a la fiscalización de la Superintendencia de Servicios Sanitarios. En tal sentido, la Corte Suprema sostuvo que "[...] De las disposiciones citadas puede desprenderse la coexistencia de los ámbitos de acción de ambos órganos administrativos Superintendencia de Servicios Sanitarios y Seremi de Salud y por lo tanto no se excluyen entre sí. En efecto, de acuerdo al artículo 67 del Código Sanitario: "Corresponde al Servicio Nacional de Salud velar porque se eliminen o controlen todos los factores, elementos o agentes del medio ambiente que afecten la salud, la seguridad y el bienestar de los habitantes en conformidad a las disposiciones del presente Código y sus reglamentos". Por su parte, el artículo 73 del mismo cuerpo normativo señala: "Prohíbese descargar las aguas servidas y los residuos industriales o mineros en ríos o lagunas, o en cualquiera otra fuente o masa de agua que sirva para proporcionar agua potable a alguna población, para riego o para balneario, sin que antes se proceda a su depuración en la forma que se señale en los reglamentos. Sin perjuicio de lo establecido en el Libro IX de este Código, la autoridad sanitaria podrá ordenar la inmediata suspensión de dichas descargas y exigir la ejecución de sistemas de tratamientos satisfactorios destinados a impedir toda contaminación". En el mismo sentido, Aguas Araucanía S.A. con Fisco de Chile (2017), en la cual se señala que "[...]el análisis de los artículos 1, 11, 34 y 45 de la Ley No 18.902, que crea la Superintendencia de Servicios Sanitarios, permite sostener que las facultades de la autoridad sanitaria para velar por la protección de la salud pública no son eliminadas por dicha ley, la cual tiene otro fin, que es la fiscalización del funcionamiento de las concesiones sanitarias y no la protección de la salud pública. En consecuencia, el Servicio de Salud que instruyó el sumario sanitario a que se refiere la causa, tiene atribuciones de orden general conforme a lo dispuesto por los artículos 67 y 161 y siguientes del Código Sanitario para instruir sumario por infracciones al Código Sanitario".

72 Así, respecto de las sanciones aplicadas por dichas entidades respecto de un mismo hecho, se ha señalado que: "[...] la actuación de la Dirección del Trabajo lo fue en el marco de sus facultades de fiscalización para velar por el cumplimiento de la normativa laboral, que incluye la protección de las remuneraciones de los trabajadores, en tanto que la decisión de la Superintendencia impugnada en autos tiene por basamento el resguardo del interés fiscal. [...] no aparece configurada la identidad de fundamento entre las infracciones cursadas al reclamante por las dos instituciones públicas mencionadas, y ello en razón especialmente de haberse lesionado distintos bienes jurídicamente protegidos. En un caso lo reprochado al actor es la vulneración de la legislación laboral, vale decir, de aquella que resguarda los derechos de los trabajadores, definida específicamente por la falta de pago de sus remuneraciones, sin que a su respecto resulte relevante ninguna otra consideración, especialmente aquella referida a la percepción por su empleador de la subvención escolar. En cambio, la multa impuesta por la autoridad de educación pretende proteger el interés fiscal, en cuanto se trata de asegurar que la mencionada subvención, que se financia con recursos públicos, sea entregada a los sostenedores que realmente tienen derecho a percibirla". Instituto de Educación Rural con Superintendencia de Educación (2015). 
agravada, es decir, la sanción prevista para la infracción más grave, aunque no se indica algún fundamento positivo para sostener dicho criterio ${ }^{73}$.

\section{Reflexión sobre los criterios seguidos por la jurisprudencia}

En definitiva, de la revisión de estos pronunciamientos se puede desprender que no existe una base estable y segura para resolver las figuras concursales en el ámbito administrativo sancionador. En primer término, no se aprecia una clara distinción entre el principio non bis in ídem, el concurso aparente de leyes penales y el concurso ideal infraccional. A su vez, los criterios para determinar la sanción tampoco son satisfactorios, sobre todo ante la falta de regulación de la materia y la posibilidad de respetar el principio de proporcionalidad, ya que la acumulación aritmética de sanciones constituye la regla general tanto para el concurso real como para el concurso ideal de infracciones administrativas.

\section{Criterios para determinar la sanción en las figuras concursales en el ámbito de las infracciones administrativas}

Los sistemas administrativos sancionadores han sido establecidos como herramientas destinadas a garantizar el cumplimiento de la normativa sectorial. Desde esta perspectiva, la finalidad última de dichos sistemas no es la aplicación de sanciones, sino que la prevención de infracciones o, en su caso, la adopción de medidas correctivas que de forma oportuna permitan resguardas los bienes jurídicos colectivos que se buscan tutelar, aun cuando se haya cometido la infracción. Por tal razón, se establecen incentivos en los casos que el propio infractor se autodenuncia o se propone un plan de cumplimiento como medidas alternativas a la sanción o para atenuar su responsabilidad ${ }^{74}$.

Ahora bien, cuando los mecanismos destinados al cumplimiento de las normas se han tornado insuficientes, ya sea porque no han podido evitar o morigerar las conductas constitutivas de infracción, la sanción surge como una herramienta inevitable. En tal sentido, la regla general estará dada por la aplicación de una sanción frente a la ocurrencia de un hecho infraccional, por lo que habrá tantas sanciones como tantos hechos infraccionales se hayan

\footnotetext{
73 Así, se ha señalado que "[...] si la multiplicidad o reiteración de conductas reprochables, por ser de diferente naturaleza, conducen a diferentes infracciones, se configuraría un concurso ideal en el que la infracción más grave absorbería o subsumiría a las de menor entidad [...] La circunstancia, entonces, que exista esta comunicabilidad de hechos que hayan contravenido distintas normas [...] configura un concurso ideal de infracciones, y habiendo una más grave que puede absorber o subsumir a la de menor entidad, solo la mayor puede aplicarse, razón por la que esta Corte procederá a acoger la reclamación en esta parte", Mauricio Orleans Cuadra con Superintendencia de Seguridad Social (2018). En un sentido similar se pronuncia la Corte Suprema en Aguas Antofagasta S.A. con Superintendencia de Servicios Sanitarios (2017), considerando $7^{\circ}$ de la sentencia de reemplazo, aunque el caso tienen los elementos de un concurso aparente de leyes y no de un concurso ideal.

74 Cordero 2014, p. 194.
} 
cometidos. En definitiva, se hace aplicación del antiguo brocardo quot delicta tot poenae, que es este caso sería tantas infracciones, tantas sanciones.

Como queda en evidencia, la aplicación estricta de este principio da lugar en muchos casos a sanciones desproporcionadas, en relación con la lesión efectiva que se ha ocasionado al bien jurídico que se está amparando. Por tal razón, desde antiguo se han formulado supuestos para evitar la acumulación matemática frente a un concurso real a partir de la unidad jurídica de acción en la configuración del hecho infraccional, como sucede con el concurso medial y los ilícitos continuados. Esta discusión también se ha trasladado al ámbito de las infracciones administrativas, ya que en todos los casos el hecho infraccional no está tipificado de la misma forma y es posible -como se ha visto- que un hecho infraccional pueda estar constituido por dos o más acciones u omisiones.

Sin embargo, los criterios que puede utilizar el legislador para atenuar la excesiva rigurosidad de la acumulación material de sanciones -como la absorción a la infracción más grave o la exasperación-, han demostrado ser contingentes tanto desde la perspectiva histórica y comparada ${ }^{75}$, por lo que exigen de una norma legal expresa que, en el caso de nuestro ordenamiento, no existe. Por tal razón, y como se ha visto, la jurisprudencia ha actuado con vacilación, no dando una solución única.

No obstante, es posible aportar algunos criterios que permitan a la Administración determinar la sanción sobre la base de elementos que respondan a la proporcionalidad que debe existir en entre el hecho infraccional y la lesión causada al bien jurídico. Aquello está unido al proceso lógico-racional que se debe seguir en la calificación jurídica que se hace de los hechos, la determinación de la norma aplicable y la forma de resolver los eventuales concursos infraccionales que se pueden presentar, y que se resume en los siguientes puntos:

1. La determinación de la naturaleza de las infracciones: la unidad de acción y el hecho infraccional

El primer paso, consiste en determinar cuál es el hecho infraccional y las acciones u omisiones que comprende. Ya hemos señalado que utilizamos el término hecho infraccional -similar al concepto de hecho punible utilizado por la dogmática penal-, en la medida que puede comprender una sola acción u omisión (unidad natural de acción) o varias acciones y/o omisiones (unidad jurídica o normativa de acción) ${ }^{76}$. Así, si bien puede haber pluralidad de acciones $u$ omisiones, no nos encontraremos ante un concurso real de infracciones, puesto que para el ordenamiento constituye un solo hecho punible.

\footnotetext{
75 Matus 2002, pp. 27-28.

76 Roxin 2014, pp. 943-962; CuRy 2005, pp. 650-653.
} 
De esta forma, constituyen un solo hecho infraccional los siguientes $\operatorname{casos}^{77}$ :

a) Cuando hay unidad natural de acción, como sucede con las infracciones simples, instantáneas o de mera actividad y en las denominadas infracciones de estado o zustand ordnungswidrigkeiten. Las primeas son infracciones en las que la lesión o puesta en peligro del bien jurídico protegido se produce en un solo momento, generando la consumación de la infracción con una sola conducta ${ }^{78}$. El infractor incurre en el ilícito una vez concluida la ejecución de la conducta. Por ejemplo, no cumplir dentro de plazo con los requerimientos de información que exija la autoridad (artículo 35 j) de la LOSMA). Por su parte, las segundas se caracterizan porque la consumación se genera por un acto formal o material que no requiere reiteración, sin embargo, presentan efectos que lesionan o ponen el peligro el bien jurídico protegido en el tiempo ${ }^{79}$. Estos efectos se mantienen por si solos, sin que medie la voluntad de infractor. Ejemplo de este tipo de infracción sería la ejecución de obras prohibidas en un parque nacional (letra p) del artículo 10 de la Ley $\left.N^{\circ} 19.300\right)$.

b) Cuando hay unidad jurídica de acción, es decir, cuando el hecho infraccional comprende dos o más acciones u omisiones, como sucede en los siguientes casos:

- Las infracciones complejas, es decir, aquellas que requieren la realización de una pluralidad de conductas descritas en la norma para su consumación, esto es, el tipo administrativo prevé la realización de varios actos o la comisión de la infracción en distintas fases ${ }^{80}$. De esta manera, la consideración aislada de cada una de las conductas puede dar lugar a ilícitos, o, por el contrario, pueden ser consideradas lícitas ${ }^{81}$.

- Las infracciones permanentes, que son aquellas en el infractor incurre en una conducta ilícita que da lugar a una situación de hecho que se mantienen en el tiempo por la persistencia de su voluntad, y sin la cual los efectos de la infracción no seguirían produciéndose ${ }^{82}$. En otros términos, la conducta

\footnotetext{
77 Respecto de la distinción de las infracciones se sigue de cerca la doctrina penal, por todos RoxIN 2014, pp. 328-341, MIR 2010, pp. 223-231 y CURY 205, pp. 651-653; y que también es tomada por los administrativistas. Véase De PALMA DEL TESO 2001, 556-557 y BACA 2011, pp. 268270, para efectos del cómputo del plazo de la prescripción.

78 De Palma del Teso 2001, pp. 556-557.

79 Gómez y SAnz 2017, p. 620.

80 De Palma del Teso 2001, pp. 569-570.

81 Gómez y SAnz 2017, pp. 628 y ss. Así sucede, por ejemplo, con la infracción de comercializar a sabiendas mercaderías, valores o especies de cualquiera naturaleza sin que se hayan cumplido las exigencias legales relativas a la declaración y pago de los impuestos que graven su producción o comercio (artículo 97 Nº del Código Tributario).

82 Esta se presenta en los casos en que se omite una declaración ante la autoridad, situación que se mantiene en el tiempo mientras no sea cumplida, como sucede en materia tributaria (artículo $97 \mathrm{~N}^{\text {s }} 1$ y 2 del Código Tributario) o aduanera (artículo 176 letra a) de la Ordenanza de Aduanas).
} 
ilícita provoca la creación de una situación antijurídica duradera que se proyecta a lo largo del tiempo dolosa o imprudentemente ${ }^{83}$.

- Las infracciones con pluralidad de acciones, es estos casos la configuración del tipo infraccional permite que su consumación puede tener lugar ya sea que se haya ejecutado una o muchas veces la acción ${ }^{84}$.

- Las infracciones con tipicidad reforzada, que considera varias acciones posibles, de forma que la ejecución de cualquiera de ellas determina su consumación ${ }^{85}$.

c) En los casos en que hay concurso real de infracciones, pero que son consideradas como un solo hecho infraccional, como ocurre con el concurso medial y las infracciones continuas. En estos casos nos encontramos con técnicas que tienen por objeto atenuar la rigurosidad de una acumulación aritmética de sanciones, si se considera cada infracción de forma independiente una de la otra y no como una unidad. Como hemos tenido ocasión de ver, la preocupación por estas figuras proviene desde la Edad Media por parte de los postglosadores, es acogida por la doctrina y la jurisprudencia, llegando en varios casos a la regulación positiva.

- El concurso medial se produce cuando estamos ante dos o más infracciones administrativas, siendo una de ellas el medio imprescindible para cometer otra ${ }^{86}$. En estos casos se entiende que hay unidad jurídica de acción, es decir, un solo hecho punible y se aplica un sistema de absorción de la sanción, es decir, se impone únicamente la sanción asignada a la infracción más grave. Si bien esta figura está regulada en el Código Penal respecto de los delitos (artículo 75), lo cierto es que su aplicación puede tener lugar des-

\footnotetext{
83 Una distinción interesante entre las infracciones permanentes y de estado la entrega la sentencia del Tribunal Supremo español de 10 de octubre de 1988 (Ar. 7461), la cual señala que la realización de la obra allí indicada (construcción de un almacén de contenedores perturbando el uso asignado por el planeamiento) constituiría una infracción de estado que se consuma en el momento en que se produce la creación de la situación antijurídica. En cambio, el desarrollo en aquella obra (almacén) de una actividad industrial constituiría una infracción permanente.

${ }^{84}$ Esta situación se presenta en los casos de las declaraciones incompletas o erróneas que realizan los contribuyentes, ya que pueden ser uno o varios los vacíos o errores, pero la conducta será sancionada siempre de la misma manera (artículo 97 N³ del Código Tributario).

${ }^{85}$ Como sucede con materia aduanera con la violación del sello o la apertura, rotura o retiro de marchamos, candados u otros cierros colocados por la Aduana en los vehículos o en los recintos - locales habilitados como almacenes particulares (artículo 176 letra b de la Ordenanza de Aduanas) o materia tributaria, en caso de sustracción, ocultación o enajenación de especies que queden retenidas en poder del presunto infractor, en caso de que se hayan adoptado medidas conservativas (artículo 97 N 14 del Código Tributario). En el ámbito sanitario, constituye infracción cualquier forma de publicación o propaganda referente a higiene, medicina preventiva o curativa y ramas semejantes que, a juicio del Servicio Nacional de Salud, tienda a engañar al público o a perjudicar la salud colectiva o individual (artículo 56 del Código Sanitario).

86 El Diccionario Panhispánico del Español Jurídico lo define como un "[...] concurso real de infracciones administrativas que tiene lugar cuando una infracción se realiza como medio o instrumento necesario para realizar otra distinta, y que se castiga con una única sanción más grave de la que correspondería a una sola de las infracciones en concurso [...]". Real Academia Española 2017, T. I, p. 534.
} 
de un punto de vista lógico en relación con la forma en que se desarrolla la acción. Así, por ejemplo, causar un daño ambiental no cumpliendo con las obligaciones de la resolución de calificación ambiental. En este caso, el solo de incumplimiento de las obligaciones impuestas en dicha resolución constituyen una infracción, pero se traducen en una infracción mayor atendido el daño ambiental que se ha provocado.

En nuestra opinión, el concurso medial debe ser apreciado como una sola infracción, pese a la reiteración de hechos o sucesos fácticos independientes y aun cuando cada uno de ellos, separadamente, puedan ser calificados como una infracción individual, sujetas a una sanción autónoma conforme a las reglas del concurso real. Sin embargo, como bien señala la doctrina, en estos casos su aplicación depende de la posibilidad de constatar la concurrencia de un vínculo de conexión entre dichos sucesos que sea de tal naturaleza que habilite a apreciar esta única realización infraccional a partir de todo el conjunto, dando forma a un caso de unidad jurídica de acción ${ }^{87}$.

- La infracción continua. Es una categoría que deriva de la figura tradicional del delito continuado desarrollado en el Derecho penal ${ }^{88}$. Se ha definido como un "[...] concurso real de infracciones administrativas consistente en la realización de una pluralidad de acciones u omisiones, constitutivas cada una de ellas de otras tantas infracciones, que infrinjan el mismo o semejantes preceptos administrativos, en ejecución de un plan preconcebido o aprovechando idéntica ocasión, y que se castiga con una única sanción, más grave de la que correspondería a una sola de las infracciones en concurso, pero no por aplicación de la garantía non bis in ídem, sino en virtud del principio de proporcionalidad"89.

Se trata de un supuesto en el cual el autor realiza una pluralidad de acciones en momentos distintos, por lo que pueden ser sancionados de forma independiente, pero considerando que todas se realizan dentro de un mismo propósito, se entiende que existe unidad jurídica de acción y, por tanto, una sola infracción. Si bien se ha discutido esta figura, particularmente en el ámbito del Derecho penal, se ha llevado a sostener por algunos autores que su creación se debe al Derecho consuetudinario ${ }^{90}$, aunque lentamente se ha regulado, como sucede con el artículo 74.1. del Código Penal Español y de ahí a pasado al Derecho administrativo a través de la Ley 40/2015, de 1 de

\footnotetext{
87 Maldonado 2015, p. 194.

88 Sus antecedentes se encuentran en los juristas medievales Julius Clarus, Prosper Farinacius, Bartolo de Sassoferrato y Baldo de Ubaldi. Véase Geerds 1961, pp. 24-27; JesCheCK y Weigend 1996, p. 708; CURY 2005, p. 654, pero ha planteado una ardua discusión para encontrar un elemento que permite unificar las distintas acciones (Novoa 1965). En general, se caracteriza porque supone pluralidad de acciones, el transcurso del tiempo para la realización de dichas acciones, que el sujeto pasivo sea el mismo (aunque no siempre se exige) y que se trate de infracciones de la misma especie. Para una visión general del tema, véase CuRY 2005, pp. 653-659; MaldonAdo 2015, pp. 123-226; MiR 2010, pp. 642-646.

89 Real Academia Española 2017, T. II, p. 1160.

90 Cury 2005, p. 653.
} 
octubre, de Régimen Jurídico del Sector Público, la cual dispone "[...] será sancionable, como infracción continuada, la realización de una pluralidad de acciones $u$ omisiones que infrinjan el mismo o semejantes preceptos administrativos, en ejecución de un plan preconcebido o aprovechando idéntica ocasión" (artículo 29.6). En todo caso, esta disposición ha planteado alguna discusión, pues no queda claro si solo debe considerarse una sola infracción y, en dicho caso, cuál de ellas debiese ser considerada ${ }^{91}$. Por lo demás, tampoco está resuelto qué sucede en el caso que la acumulación lleve a una calificación más grave de la infracción y, por tanto, que la sanción fuese superior a la simple acumulación matemática de cada infracción ${ }^{92}$. Por tal razón, se propone considerar a la infracción continuada solo en cuanto implique un beneficio para el infractor ${ }^{93}$.

\section{La resolución de un eventual concurso de leyes infraccionales}

Ya hemos distinguido entre la figura del concurso de leyes y el concurso de infracciones administrativas. En este caso, lo primero que se debe despejar dice relación con la ley que resulta aplicable, particularmente en aquellos casos en que el hecho infraccional puede ser subsumido en los tipos infracciones previstos en dos o más leyes. Así, el resultado esperado es que frente a un hecho solo podrá aplicarse una ley, quedando desplazadas los demás, para lo cual podremos recurrir a los criterios clásicos que se han formulado: especialidad, consunción, subsidiariedad y alternatividad, encontrando en nuestra doctrina mayor consenso en los dos primeros ${ }^{94}$.

No podemos desconocer que este procedimiento se encuentra estrechamente vinculado al anterior, puesto que los tipos infraccionales son creaciones normativas y, por tanto, necesariamente la determinación de los elementos del hecho punible llevará a una discusión respecto de la ley que resulta aplicable. Así, un primer problema será determinar si el hecho reúne los elementos para configurar una infracción administrativa ${ }^{95} \mathrm{y}$, en caso de que el mismo hecho sea subsumido por más de tipo legal, se debe establecer cuál resulta aplicable y cuál debe ser desplazado. Esto se aprecia principalmente cuando se hace la calificación jurídica del hecho punible, especialmente en leyes que establecen un tipo infraccional simple y otros agravados, como ha sucedió en materia eléctrica ${ }^{96}$ y sanitaria ${ }^{97}$. Aunque llame

\footnotetext{
91 Gómez 2017, p. 606.

92 ÍDEM, p. 607.

93 IDEM, Pp. 607 y 608.

94 Matus 2002, pp. 31-33; Cury 2005, pp. 668-671.

95 Por lo demás, es habitual que aparezcan casos en que se imponga una sanción administrativa sin que se verifique la existencia de contravención normativa alguna que le sirva de sustento, ya que muchas veces la infracción se construye a partir de la interpretación que se hace de la norma administrativa. Véase Sociedad Almondale Valle SpA con Superintendencia de Educación (2018).

96 GasAtacama Chile S.A. con Superintendencia de Electricidad y Combustibles (2020), considerando $15^{\circ}$.

97 Aguas Antofagasta S.A. con Superintendencia de Servicios Sanitarios (2017), considerando $9^{\circ}$.
} 
la atención, se han planteado casos en que se ha pretendido aplicar ambas sanciones $^{98}$.

Por otra parte, nuestra jurisprudencia ha reconocido la figura ${ }^{99}$, pero también la ha confundido con el concurso ideal de infracciones ${ }^{100}$ que, desde el punto de vista del razonamiento, corresponde a una etapa posterior, esto es, cuando la concurrencia normativa no es posible de resolver conforme a algunos de los criterios que entrega la teoría del conflicto aparente de leyes.

3. Determinación de sanciones en caso de concurso o pluralidad de infracciones administrativas

El paso siguiente se presenta cuando un hecho puede constituir dos o más infracciones administrativas (concurso ideal) o cuando dos o más hechos realizados por un mismo sujeto constituyen dos o más infracciones, sin que ninguno de ellos se hubiese cometido después de haber sido sancionado por alguno de ellos (concurso real).

En estos casos la solución descansa sobre la base del principio de proporcionalidad, es decir, que la reacción punitiva sea coherente con la gravedad de los hechos infracionales que se están sancionando. Sin embargo, nos encontramos con la ausencia de una norma que regule esta materia. Además, no contamos con disposición alguna en el orden administrativo que se remita a las normas penales, particularmente los artículos 74 y 75 del Código Penal, complementado por el artículo 351 del Código Procesal Penal.

El problema es que, si bien podemos utilizar las categorías y técnicas elaboradas por el Derecho penal, hay determinaciones que solo se pueden adoptar en a nivel legal, pues responden a una decisión de política represiva, como es la aplicación de las reglas de absorción, absorción agravada o de exasperación. Por lo tanto, el planteamiento que se puede hacer se encuentra sujeto a limitaciones que son insoslayable ante la falta de normas positivas.

\section{a) La acumulación de sanciones como regla general}

La potestad sancionadora de la Administración está dominada por el principio de legalidad, como sucede con todas las formas de actuar y el ejercicio de sus atribuciones por parte de los órganos del Estado. Esta legalidad se expresa en varios aspectos: i) la determinación de los ilícitos administrativos; ii) la atribución de la potestad sancionadora la Administración; ii) la

\footnotetext{
98 En Aguas Antofagasta S.A. con Superintendencia de Servicios Sanitarios (2017), el voto de minoría afirma que: "[...] la autoridad Administrativa, al imponer una sanción por infringir el artículo 11 letra a) de la Ley No 18.902 y otra por infringir la letra b) de la referida disposición, no ha vulnerado el principio del non bis in ídem, pues el bien jurídico protegido es distinto, según se analizó, por lo que la supuesta unidad de hecho, es irrelevante".

99 Empresa de Transportes Rurales Ltda con Inspección del Trabajo de Antofagasta (2016): Corte de Apelaciones de Antofagasta, 18 de noviembre de 2016. Rol N 172-2016, considerando $6^{\circ}$.

100 Aguas Antofagasta S.A. con Superintendencia de Servicios Sanitarios (2017), considerando $7^{\circ}$ de la sentencia de reemplazo.
} 
determinación de la sanción, y ii) el procedimiento para hacerla efectiva. En principio, cada uno de estos aspectos están sujetos a la determinación legal (potestades regladas), no obstante, es posible que el legislador pueda otorgar un mayor margen de discrecionalidad a la Administración para iniciar el procedimiento, instruirlo o aplicar una sanción. Sin embargo, mientras aquello no ocurra, el ejercicio de la potestad sancionadora es de carácter reglado, por lo que, ante la comisión de una infracción, necesariamente se debe iniciar un procedimiento administrativo y aplicar una sanción. Dicho, en otros términos, dado el supuesto de hecho (conducta constitutiva de infracción), la Administración tiene el deber de sancionar. Así, todo hecho constitutivo de infracción debe tener una sanción correlativa, salvo que la ley establezca reglas especiales para resolver un concurso infraccional. De esta forma, en caso de concurso real de infracciones, procede la acumulación aritmética de sanciones, esto es, por cada infracción se deberá aplicar una sanción de manera independiente.

Esta regla también resulta aplicable al concurso ideal infraccional. Este problema se ha vinculado estrechamente unido al principio non bis in ídem, aunque con soluciones diversas. En efecto, en el caso en que una conducta pueda ser sancionadas más de una vez sobre la base de los mismos fundamentos (identidad de hecho y de fundamento), es plenamente aplicable el principio de prohibición de doble valoración o non bis in ídem ${ }^{101}$. Sin embargo, cuando se produce la afectación de bienes jurídicos diversos, la cuestión cambia drásticamente, pues no existe una plena identidad y esta prohibición no resultaría aplicable. En el Derecho penal se ha optado en estos supuestos por dar un tratamiento más benigno, considerando que se trata de la realización de una sola conducta. Por tal razón, el Código Penal chileno establece que se impondrá la pena mayor asignada al delito más grave (inciso $2^{\circ}$ del artículo 75).

Por su parte, la ausencia de una norma en el ámbito administrativo ha llevado a un tratamiento diverso del concurso ideal infraccional en Chile, optando por la acumulación aritmética de sanciones. Así se desprende de algunas normas que regulan la materia, como sucede en los temas ambientales, al disponer que "En ningún caso se podrá aplicar al infractor, por los mismos hechos y fundamentos jurídicos, dos o más sanciones administrativas" (artículo 60 inciso $2^{\circ}$ LOSMA). Como se puede apreciar, esta disposición hace la aplicación del principio non bis in ídem, el cual exige identidad de persona (infractor), de hecho (infracción) y de fundamentos (bien jurídico). Sin embargo, y como hemos señalado, también se desprende una conclusión que se proyecta al concurso ideal de infracciones, puesto que ante la ausencia de igual fundamento (solo hay identidad de infractor $y$, de hecho), no resulta aplicable dicha norma y, por tanto, se acumulan de forma aritmética ambas sanciones.

101 GÓmez 2017, 115. 
Esta interpretación es la que ha seguido mayoritariamente nuestra jurisprudencia, como se ha visto en varias de las sentencias analizadas ${ }^{102}$, aunque hay casos en que se ha aplicado la regla de absorción agravada, aunque sin fundamento positivo que lo respalde ${ }^{103}$. En todo caso, también nos encontramos con un problema de carácter procedimental, pues no existe una regulación general respecto procedimientos sancionadores paralelos o sucesivos que pueden llevar adelante diversos órganos administrativos respecto de un mismo hecho infraccional y la forma de establecer instancias de prevalencia o coordinación, salvo excepciones ${ }^{104}$.

En nuestra opinión, estamos ante una solución que no resulta del todo adecuada y exige necesariamente una revisión que permita aplicar un criterio similar al previsto en la legislación penal, pues los fundamentos de dicha regla no difieren en lo absoluto de lo que ocurre en materia de infracciones administrativas. Por tal razón, pensar en aplicar el artículo 75 del Código Penal por analogía in melior, como propone Alejandro Nieto ${ }^{105}$, parece algo del todo razonable, inclinándonos por la sanción asignada a la infracción más grave, que es la que mejor responde al marco constitucional y, particularmente, al principio de proporcionalidad reconocido por nuestra jurisprudencia ${ }^{106}$.

102 Verdenova S.A. con Secretaría Regional Ministerial de Salud de la Región Metropolitana (2016), considerandos $8^{\circ}$ y $9^{\circ}$; Procesadora Insuban Limitada con Secretaría Regional Ministerial de Salud de la Región Metropolitana (2017), considerando 8; Constructora Nueva Tarapacá S.A. con Secretaría Regional Ministerial de Salud de la Región Metropolitana (2018), considerando $2^{\circ}$, Instituto de Educación Rural con Superintendencia de Educación (2015).

103 Así, se ha señalado que "[...] si la multiplicidad o reiteración de conductas reprochables, por ser de diferente naturaleza, conducen a diferentes infracciones, se configuraría un concurso ideal en el que la infracción más grave absorbería o subsumiría a las de menor entidad [...] La circunstancia, entonces, que exista esta comunicabilidad de hechos que hayan contravenido distintas normas [...] configura un concurso ideal de infracciones, y habiendo una más grave que puede absorber o subsumir a la de menor entidad, solo la mayor puede aplicarse, razón por la que esta Corte procederá a acoger la reclamación en esta parte". Mauricio Orleans Cuadra con Superintendencia de Seguridad Social (2018). En un sentido similar se pronuncia la Corte Suprema en Aguas Antofagasta S.A. con Superintendencia de Servicios Sanitarios (2017), considerando $7^{\circ}$ de la sentencia de reemplazo, aunque el caso tienen los elementos de un concurso aparente de leyes y no de un concurso ideal.

104 Así sucede con el artículo 59 de la Ley Orgánica de la Superintendencia de Medio Ambiente contenida en la Ley $\mathrm{N}^{\circ} 20.417$, la cual dispone que: "Iniciado un procedimiento administrativo sancionador por parte de la Superintendencia no podrá ningún organismo sectorial con competencia ambiental, por los mismos hechos, iniciar un procedimiento administrativo sancionatorio de competencias propias o denunciarlos a la justicia civil, a menos que la Superintendencia se declare incompetente. Los organismos sectoriales con competencia ambiental que, en el ejercicio de sus funciones, tomen conocimiento de estas infracciones estarán obligados a denunciarlos a la Superintendencia. En caso de que alguno de estos organismos iniciare un procedimiento respecto de materias que son competencia de la Superintendencia, ésta, de oficio o a petición de interesado, podrá solicitarle que se declare incompetente y le remita todos los antecedentes para iniciar el procedimiento respectivo".

105 Nieto 2011, p. 132.

106 La Contraloría ha hecho uso constante de este principio en el ámbito de la responsabilidad disciplinaria, como en los dictámenes Nos. 4.767 y 65.855, de 2012. El Tribunal Constitucional ha aplicado este principio en general en Honorable Cámara de Diputados (1995), considerando $47^{\circ}$; y Honorable Cámara de Diputados (1998), considerando $21^{\circ}$. En relación con las sanciones admi- 
b) Las excepciones a la acumulación de sanciones

i. La unidad de sanción

La excepción a la regla general de la acumulación de sanciones son aquellos casos en que existiendo pluralidad de hechos infraccionales, se produce la unificación de todos en uno solo, como sucede con el concurso medial y en las infracciones continuas, como acabamos de ver. En ambos casos estamos ante un concurso real de infracciones, pero en el primero se produce la absorción de la conducta infraccional que constituye un medio para cometer otra infracción de mayor gravedad; mientras que el segundo hay pluralidad de hechos infraccionales cometidos en el tiempo, pero que en razón de existir una identidad de propósito a partir de un plan preconcebido o aprovechando una determinada ocasión, se entiende que constituye una sola infracción.

Distinta es la situación en donde existe unidad jurídica acción, ya que, a pesar de existir pluralidad de acciones u omisiones (infracciones complejas, permanentes, de pluralidad de acciones y con tipos reforzados), no estamos ante un concurso real de infracciones, sino que ante un solo hecho infraccional.

\section{ii. La imposibilidad de ejecución de las sanciones}

Otra excepción a la acumulación de sanciones la constituye la imposibilidad de ejecución de alguna de ellas, como consecuencia de la imposición previa de otra. En efecto, si bien la autoridad puede imponer varias sanciones, es posible que en ciertos supuestos no sea factible ejecutarlas todas, sea de manera simultánea y/o sucesiva. Así, si dos infracciones son sancionadas con la revocación de una autorización de funcionamiento y otra con la clausura del establecimiento, solo una de ellas podrá ejecutarse, quedando la otra subsumida en la aplicación de la primera. En este caso no existe una figura concursal de unidad de sanción frente a una pluralidad de infracciones, sino que simplemente la primera de las sanciones impuestas cumplió los objetivos que perseguían todas las demás.

\section{Conclusiones}

En el Derecho chileno la inexistencia de una norma general que regule con carácter supletorio el ejercicio de los poderes represivos de los órganos administrativos plantea la interrogante respecto de las normas que deben ser observadas en caso de vacíos en las regulaciones sectoriales respectivas, como ocurre en el caso del concurso infraccional. Si bien las soluciones contempladas en la legislación comparada pueden resultar de interés, nuestra jurisprudencia no ha entregado una base estable y segura para resolver las figuras concursales en el ámbito administrativo sancionador. En primer término, no hay en sus pronunciamientos una clara distinción entre el principio

nistrativas en particular, se puede ver María Angélica Sánchez Vogel y otros (2010), considerando $14^{\circ}$. La Corte Suprema también sigue este principio, como en Gasco GLP s.a. contra Superintendencia de Electricidad y Combustibles (2017), considerando $10^{\circ}$. 
non bis in ídem, el concurso aparente de leyes penales y el concurso ideal infraccional. A su vez, los criterios para determinar la sanción tampoco son satisfactorios, sobre todo ante la falta de regulación de la materia y la posibilidad de respetar el principio de proporcionalidad.

En tal sentido, la conclusión de este trabajo es que en Chile el concurso infraccional da lugar a una acumulación de sanciones. Sin embargo, una regla tan rigurosa se puede matizar bajo determinados supuestos en los que se puede aplicar una sanción, como sucede en los casos de pluralidad de acciones, pero de un solo hecho infraccional, como ocurre con el concurso medial y las infracciones continuas. Además, parece razonable aplicar en el caso del concurso ideal una regla de absorción a la sanción de la infracción más grave, no solo teniendo como referencia la legislación penal, sino también el principio de proporcionalidad reconocido a nivel constitucional.

En todo caso, constituye un paso previo analizar la forma de establecer una regla de coordinación o prevalencia frente a procedimientos administrativos sancionadores paralelos o sucesivos, especialmente cuando son instruidos por dos o más órganos administrativos.

En definitiva, si bien las deficiencias regulatorias no permiten ser superadas por la aplicación del principio non bis in ídem, es posible establecer criterios para atenuar la regla de la acumulación matemática de sanciones administrativas. En todo caso, el problema exige una revisión a nivel legislativo que no solo sea una mera proyección de las soluciones que se han dado en el ámbito penal, sino que considere el sentido y función que se asigna a las sanciones administrativas en el marco de los deberes que debe cumplir la Administración del Estado.

\section{Bibliografía citada}

alarcón Sotomayor, Lucía (2010). Principio non bis in ídem. En: Lozano Cutanda, Blanca [dir.], Diccionario de sanciones administrativas. Madrid, lustel, pp. 762-779.

ArCe Aggeo, Miguel Ángel (1996). Concurso de delitos en materia penal. Buenos Aires, Editorial Universidad.

Aróstica Maldonado, Iván (1987). Algunos problemas del Derecho Administrativo Penal, en Revista de Derecho, Universidad de Concepción, N 182, pp. 71-81.

Aróstica Maldonado, Iván (1991): Un lustro de sanciones administrativas (1988-1992), en: Revista de Derecho Público, Universidad de Chile, №50, pp. 173-195.

BACA Oneto, Víctor (2011). La Prescripción de las Infracciones y su Clasificación en la Ley del Procedimiento Administrativo General. En especial, análisis de los supuestos de infracciones permanentes y continuada", en Derecho y Sociedad, N 37, pp. 265-266.

BeRMúdez SOTO, Jorge (2014). Reglas para la imposición de sanciones ambientales, en ArANCIBIA, Jaime y JAÑA, Juan Pablo [coords.], Sanciones Administrativas. Santiago, Legal Publishing, pp. 609-632.

Cano Campos, Tomás (2001). Non bis in ídem, prevalencia de la vía penal y teoría de los concursos en el Derecho administrativo sancionador. Revista de Administración Pública, No 156, pp. 191-250.

Cano Campos, Tomás (2010). Medio ambiente, potestad sancionadora. En: Lozano Cutanda, Blanca (dir.), Diccionario de sanciones administrativa. Madrid, lustel, pp. 556-578. 
Cordero, Eduardo (2013). Concepto y naturaleza de las sanciones administrativas en la doctrina y jurisprudencia chilena, en Revista de Derecho Universidad Católica del Norte, vol. 20, N $1^{\circ} 1$, pp. 79-103.

CORDERO, Eduardo (2014). Los principios y reglas comunes al procedimiento administrativo sancionador, en ArANCIBIA, Jaime y JAÑA, Juan Pablo [coords.], Sanciones Administrativas. Santiago, Legal Publishing, pp. 189-215.

Cury, Enrique (2005). Derecho Penal. Parte General. Santiago, Ediciones Universidad Católica de Chile, $812 \mathrm{pp}$.

De Palma del Teso, Ángeles (2001). Infracciones administrativas continuadas, las infracciones permanentes, las infracciones de estado y las infracciones de pluralidad de actos: distinción a efectos del cómputo del plazo de prescripción. Revista Española de Derecho Administrativo, $\mathrm{N}^{\circ} 112$, pp. 556-557.

De León Villalba, Francisco Javier (1998). Acumulación de Sanciones Penales y Administrativas. Sentido y alcance del principio "ne bis in idem", Barcelona, Bosch.

Etcheberry, Alfredo (1998). Derecho Penal. Parte General. Santiago, Editorial Jurídica de Chile, $3^{\text {a }}$ edición, 1.502 pp.

Garrido Montt, Mario (2003). Derecho Penal. Parte General. Santiago, Editorial Jurídica de Chile, $3^{\text {a }}$ edición, 414 pp.

GEERDS, Friedich (1961). Zur Lehre von der Konkurrenz im Strafrecht, Hansischer Gildenverlag, Joachim Heitmann und Co., Hamburg.

Gómez GonzÁlez, Rosa Fernanda (2017). "El non bis in ídem en el Derecho Administrativo sancionador. Revista de Derecho (Valparaíso), XLIX, pp. 101-138.

Gómez Tomillo, Manuel y Sanz Rubiales, Iñigo (2013). Derecho Administrativo Sancionador. Parte General. Teoría General y Práctica del Derecho Penal Administrativo. Pamplona, Thomson Reuters, $3^{\text {a }}$ edición, 1.070 pp.

Gómez Tomillo, Manuel y Sanz Rubiales, Íñigo (2017). Derecho Administrativo Sancionador. Parte General. Navarra, Thomson Reuters Aranzadi, 4ª edición, 1.011 pp.

HuneEus, Jorge (1891). La Constitución ante el Congreso, Santiago, Cervantes.

Izouierdo Carrasco, Manuel (2001). La determinación de la sanción administrativa. Justicia Administrativa, Revista de Derecho Administrativo, N Extra 1, pp. 207-257.

JESCHECK, Hans-Heinrich y WEIGEND, Thomas (1996). Lehrbuch des Strafrechts, Allgemainer Teil, Duncker \& Humblot, Berlín.

Letelier Wartenberg, Raúl (2017). Garantías penales y sanciones administrativas, en Política criminal, vol.12, n.24, pp. 622-689.

Londoño Martínez, Fernando (2014). Tipicidad y legalidad en el derecho administrativo-sancionatorio, en: Revista de Derecho (Valdivia), Vol. 27, № 2, pp.147-167.

Maldonado Fuentes, Francisco (2015). "Delito continuado y concurso de delitos", en Revista

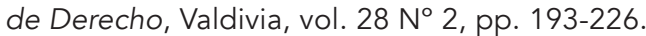

Matus Acuña, Jean Pierre (2000). La teoría del concurso (aparente) de leyes en la dogmática alemana, desde sus orígenes hasta el presente (primera parte). lus et Praxis, Año 6, $N^{\circ} 2$, pp. 357-400.

Matus Acuña, Jean Pierre (2002). La teoría del concurso aparente de leyes y el "resurgimiento" de la ley en principio desplazada, en Revista de Derecho, Coquimbo, N 9, pp. 27-68.

MIR PuIG, Santiago (2010). Derecho penal. Parte General. $8^{\mathrm{a}}$ ed. $3^{\mathrm{a}}$ reimp. Montevideo Buenos Aires, B de F, 2010.

MıтsCH, Wolfgan (1995). Recht der Ordungswidrigkeiten, Berlin, Springer, 1995.

Nieto, Alejandro (2005). Derecho Administrativo Sancionador. Madrid, Tecnos, $4^{a}$ edición, 592 pp.

NiEto, Alejandro (2012). Derecho Administrativo Sancionador. Madrid, Tecnos (5a edición), 612 pp.

Novoa Monreal, Eduardo (2005). Curso de Derecho Penal chileno $3^{\circ}$ ed. T. I, Santiago, Editorial Jurídica de Chile, 2005, I, 585 pp.

NovoA, Eduardo (2005). Curso de Derecho Penal Chileno. Santiago, Editorial Jurídica de

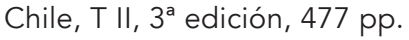


Oliver Calderón, Guillermo (2013). La exasperación de la pena en el concurso material de delitos: la reiteración de delitos de la misma especie, en Revista de Derecho, Valdivia, vol. XXVI, N² 2 pp. 167-188.

Parejo Alfonso, Luciano (2008). Lecciones de Derecho Administrativo. Valencia, Editorial Tirant lo Blanch, $2^{\mathrm{a}}$ edición, $878 \mathrm{pp}$.

Politoff, Sergio; Matus, Jean Pierre y Ramírez, María Cecilia (2003). Lecciones de Derecho Penal. Parte General. Santiago, Editorial Jurídica de Chile, $2^{\mathrm{a}}$ edición, 616 pp.

Real Academia Española (2017). Diccionario Panhispánico del Español Jurídico. Madrid, Santillana.

Rebollo Puig, Manuel, Alarcón Sotomayor, Lucía, Bueno Armijo, Antonio, Izouierdo Carrasco, Manuel (2010). Derecho Administrativo Sancionador. Valladolid, Lex Nova, 1050 pp.

Rebollo Puig, Manuel (1989). Potestad Sancionadora, Alimentación y Salud Pública, Madrid, INAP.

Rodriguez Collao, Luis (1987). Bases para distinguir entre infracciones criminales y administrativas. Revista de Derecho, Valparaíso No 11, pp. 117 y 163.

Román Cordero, Cristián (2008). Derecho Administrativo Sancionador: Ser o no ser. He ahí el dilema, en: Pantoja Bauzá, Rolando (coord.). Derecho Administrativo: 120 años de cátedra. Santiago, Editorial Jurídica de Chile, pp.107-136.

Roxin, Claus (2014). Derecho Penal. Parte General. T. II, Madrid, Civitas.

SAnz Morán, Ángel José (1986). El concurso de delitos: aspectos de política legislativa. VaIladolid, Universidad, Secretariado de Publicaciones.

Sото KLoss, Eduardo (1979/1980). Derecho administrativo Penal. Notas para el estudio de la potestad sancionadora de la administración, en Boletín de Investigaciones, Facultad de derecho de la Pontificia Universidad Católica de Chile, Nos 44-45, pp. 95-103.

Vallejo, Rodrigo y Guiloff, Matías (2013). Ni juez, ni parte: La competencia sancionadora de la administración y la metodología del derecho administrativo, en X Jornadas Nacionales de Derecho Administrativo.

Van Weezel, Alex (2017). Sobre la necesidad de un cambio de paradigma en el derecho sancionatorio administrativo, en Política Criminal, vol.12, N²4, pp.997-1043.

Vergara Blanco, Alejandro (2004): Esquema de los principios del Derecho Administrativo Sancionador, en: Revista de Derecho, Universidad Católica del Norte, año 11, № 2, pp. 137-147.

\section{Jurisprudencia citada}

Administradora de Naves Humboldt Limitada con Inspección Provincial del Trabajo de Valparaíso (2018): Corte de Apelaciones de Valparaíso, 12 de enero de 2018. Rol Nº 702-2017.

Aguas Araucanía S.A. con Secretaría Regional Ministerial de Salud de la Región de la Araucanía (2018): Corte Suprema, Tercera Sala, 26 de febrero de 2018. Rol No 12.262-2017.

Aguas Araucanía S.A. con Fisco de Chile (2017): Corte Suprema, Tercera Sala, 25 de septiembre de 2017. Rol № 100.752-2016.

Aguas Antofagasta S.A. con Superintendencia de Servicios Sanitarios (2017): Corte Suprema, Tercera Sala, 3 de agosto de 2017. Rol No 88.935-2016.

Concremag S.A. con Inspección Provincial del Trabajo de Magallanes (2015): Corte de Apelaciones de Punta Arenas, 12 de enero de 2016. Rol № 90-2015.

Constructora Nueva Tarapacá S.A. con Secretaría Regional Ministerial de Salud de la Región Metropolitana (2018): Corte de Apelaciones de Santiago, 27 de febrero de 2018. Rol No 7681-2017.

Corporación Municipal de Educación Salud Cultura y Atención al menor de Quilpué con Superintendencia de Educación (2019): Corte de Apelaciones de Valparaíso, 14 de marzo de 2019. Rol No 60-2018.

Empresa de Transportes Rurales Ltda. con Inspección del Trabajo de Antofagasta (2016): Corte de Apelaciones de Antofagasta, 18 noviembre 2016. Rol N¹72-2016.

Empresa Nacional de Electricidad S.A. c. Superintendencia del Medio Ambiente (2015): Tercer Tribunal Ambiental, 27 de marzo de 2015. Rol N R6-2014. 
Esteban Guic y Compañía Ltda. con Inspección Provincial del Trabajo Coyhaique (2016): Juzgado de Letras del Trabajo de Coyhaique, 5 octubre 2016. Rol I-9-2016

Esteban Guic y Compañía Ltda. con Inspección Provincial del Trabajo Coyhaique (2017): Corte de Apelaciones de Coyhaique, 28 marzo 2017. Rol Nº 5-2017

Farmacias Cruz Verde S.A. con Inspección Comunal del Trabajo de Viña del Mar (2016): Corte de Apelaciones de Valparaíso, 2 de mayo de 2016. Rol N 112-2016.

Farmacias Cruz Verde S.A. con Inspección Provincial del Trabajo (2016): Corte de Apelaciones de Valparaíso, 9 de febrero de 2016. Rol № 491-2015.

FASA Chile S.A. con Inspección Provincial del Trabajo (2015): Corte de Apelaciones de Temuco, 27 de noviembre de 2015. Rol No 223-2015.

Fisco con Dorr Zegers y otros (2014): Corte Suprema, 30 de octubre de 2014. Rol No 10792014 (casación).

GasAtacama Chile S.A. con Superintendencia de Electricidad y Combustibles (2020): Corte Suprema, Tercera Sala, 15 de enero de 2020. Rol No 14.991-2019.

Gasco GLP S.A. contra Superintendencia de Electricidad y Combustibles (2017): Corte Suprema, Tercera Sala, 14 de marzo de 2017. Rol № 68.723-2016.

Honorable Cámara de Diputados (1998): Tribunal Constitucional, 20 de octubre de 1998 (Requerimiento de un grupo de Diputados acerca del proyecto de ley que rebaja la tasa de los aranceles a las importaciones e introduce modificaciones a otras normas tributarias y económicas.) Rol No 280.

Honorable Cámara de Diputados (1995): Tribunal Constitucional, 30 de octubre de 1995 (Requerimiento de un grupo de Diputados respecto del artículo $1^{\circ}$, inciso tercero; artículo $9^{\circ}$, inciso primero; artículo 20, inciso segundo, y artículo 43, inciso segundo, del proyecto de ley sobre "Libertad de expresión, información y ejercicio del periodismo") Rol N 226.

Honorable Cámara de Diputados (2017). Tribunal Constitucional, 26 de diciembre de 2017 (control de constitucionalidad del proyecto de ley, aprobado por el Congreso Nacional, enviado por la Cámara de Diputados y que introduce modificaciones al marco normativo que rige las aguas en materia de fiscalización y sanciones) Rol N 3.958-17.

Honorable Cámara de Diputados (2018). Tribunal Constitucional, 18 de enero de 2018 (control de constitucionalidad del proyecto de ley, aprobado por el Congreso Nacional, enviado por la Cámara de Diputados y que modifica la Ley N 19.496, sobre Protección de los Derechos de los Consumidores) Rol N 4.012-17.

Inspección Comunal del Trabajo con Faenadora San Vicente Ltda. (2009): Corte Suprema, 24 de marzo de 2009. Rol No 196-09.

Instituto Alemán de Puerto Montt con Inspección del Trabajo de Puerto Montt (2016): Corte de Apelaciones de Puerto Montt, 4 de febrero de 2016. Rol № 183-2015.

Instituto de Educación Rural con Superintendencia de Educación (2015): Corte Suprema, Tercera Sala, 17 de febrero de 2015. Rol No 1825-2015.

Instituto de Educación Rural con Superintendencia de Educación (2015): Corte Suprema, Tercera Sala, 25 de mayo de 2015. Rol № 1823-2015.

María Angélica Sánchez Vogel y otros (2010): Tribunal Constitucional, 26 de octubre de 2010 (Requerimiento de inaplicabilidad por inconstitucionalidad de María Angélica Sánchez Vogel y otros, respecto del artículo 169 del Código Sanitario, en recurso de amparo rol No 3073 - 2009 de la Corte de Apelaciones de Santiago) Rol No 1.518.

Mauricio Orleans Cuadra con Superintendencia de Seguridad Social (2018): Corte de Apelaciones de Santiago, 9 de agosto de 2018. Rol No 6537-2016.

Minera Esparta Limitada (ex Minera Española Chile Limitada) con Superintendencia del Medio Ambiente (2015): Segundo Tribunal Ambiental, 8 septiembre 2015. Rol C Nº 04-2015.

Ministerio de Interior con Silva Valdes y otros (2013): Corte suprema, 4 octubre 2013. Rol $\mathrm{N}^{\circ} 8278-2013$.

Procesadora Insuban Limitada con Secretaría Regional Ministerial de Salud de la Región Metropolitana (2017): Corte Suprema, Tercera Sala, 25 de julio de 2017. Rol № 1007222016. 
Rendic Hermanos S.A. con Dirección del Trabajo (2020): Corte de Apelaciones de Valdivia, 16 de marzo de 2020 . Rol No 18-2020.

Rubén Cruz Pérez y otros en contra de la Superintendencia del Medio Ambiente (2013). Segundo Tribunal Ambiental de Santiago, 3 marzo 2014. Rol Nº 6-2013.

Sociedad Almondale Valle SpA con Superintendencia de Educación (2018): Corte Suprema, Tercera Sala, 29 de mayo de 2018. Rol N 45.644-2017.

Sociedad Eléctrica Santiago S.A contra Superintendencia del Medio Ambiente (2014). Segundo Tribunal Ambiental de Santiago, 12 de septiembre de 2014. Rol No 23-2013.

Sociedad Marítima y Comercial Somarco Limitada con Comisión Regional del Medio Ambiente de Arica y Parinacota (2018). Corte Suprema, Tercera Sala, 23 de abril de 2018. Rol No 21.651-2017.

Sociedad Patricio Otero y Compañía Limitada con Inspección Comunal del Trabajo de Viña del Mar (2016): Corte de Apelaciones de Valparaíso, 23 de noviembre de 2016. Rol $\mathrm{N}^{\circ} 466-2016$.

Verdenova S.A. con Secretaría Regional Ministerial de Salud de la Región Metropolitana (2016): Corte Suprema, Tercera Sala. Rol N 43.460-2016.

VTR Wireless S.A. con Ministro de Transportes y Telecomunicaciones (2014): Corte de Apelaciones de Santiago, 4 de diciembre de 2014. Rol Nº670-2014. 